IZA DP No. 8911

Long Work Hours and Health in China

Peng Nie

Steffen Otterbach

Alfonso Sousa-Poza

March 2015 


\title{
Long Work Hours and Health in China
}

\author{
Peng Nie \\ University of Hohenheim
}

Steffen Otterbach

University of Hohenheim

and IZA

\author{
Alfonso Sousa-Poza \\ University of Hohenheim \\ and IZA
}

\section{Discussion Paper No. 8911 \\ March 2015}

\author{
IZA \\ P.O. Box 7240 \\ 53072 Bonn \\ Germany \\ Phone: +49-228-3894-0 \\ Fax: +49-228-3894-180 \\ E-mail: iza@iza.org
}

Any opinions expressed here are those of the author(s) and not those of IZA. Research published in this series may include views on policy, but the institute itself takes no institutional policy positions. The IZA research network is committed to the IZA Guiding Principles of Research Integrity.

The Institute for the Study of Labor (IZA) in Bonn is a local and virtual international research center and a place of communication between science, politics and business. IZA is an independent nonprofit organization supported by Deutsche Post Foundation. The center is associated with the University of Bonn and offers a stimulating research environment through its international network, workshops and conferences, data service, project support, research visits and doctoral program. IZA engages in (i) original and internationally competitive research in all fields of labor economics, (ii) development of policy concepts, and (iii) dissemination of research results and concepts to the interested public.

IZA Discussion Papers often represent preliminary work and are circulated to encourage discussion. Citation of such a paper should account for its provisional character. A revised version may be available directly from the author. 
IZA Discussion Paper No. 8911

March 2015

\section{ABSTRACT}

\section{Long Work Hours and Health in China*}

Using several waves of the China Health and Nutrition Survey (CHNS), this study analyzes the effect of long work hours on health and lifestyles in a sample of 18- to 65-year-old Chinese workers. Although working long hours does significantly increase the probabilities of high blood pressure and poorer reported health, the effects are small. Also small are the negative effects of long work hours on sleep time, fat intake, and the probabilities of sports participation or watching TV. We find no positive association between work time and different measures of obesity and no evidence of any association with calorie intake, food preparation and cooking time, or the sedentary activities of reading, writing, or drawing. In general, after controlling for a rich set of covariates and unobserved individual heterogeneity, we find little evidence that long work hours affect either the health or lifestyles of Chinese workers.

JEL Classification: I10, I12, J22, J81

Keywords: long work hours, health, lifestyle, China

Corresponding author:

Peng Nie

University of Hohenheim

Institute for Health Care \& Public Management

Fruwirthstr. 48

70599 Stuttgart

Germany

E-mail: peng_nie@uni-hohenheim.de 
IZA Discussion Paper No. 8911

March 2015

\section{NON-TECHNICAL SUMMARY}

China has one of the longest weekly work hours in the world, and it is claimed that about 600,000 Chinese people die every year because of "Guolaosi" - death by overwork (Monet, 2014). The literature in several academic disciplines provides evidence that long work hours can be detrimental to health - particularly showing adverse health effects of long work hours on subjective health. However, this large body of literature is dominated by research in Western countries, and results are mixed with regards to objective health outcomes. For China especially, the empirical evidence of such a relationship between long work hours and health is limited to only three cross-sectional studies using subjective (self-reported) health measures. Moreover, the results of these studies are mixed.

Thus, the aim of our study is to examine the impact of long work hours on health among Chinese employees aged 18-65. Using longitudinal data from the China Health and Nutrition survey (CHNS), this study is the most comprehensive analysis for China, where possible adverse health effects of overwork become an important health issue. We analyze a broad array of health measures, including not only measures of subjective health but also several measures of objective health (e.g., high blood pressure and obesity), and additionally explore several possible pathways through which long work hours could affect health. In particular, we assess the relation between long work hours and specific lifestyles, such as time spent sleeping, preparing meals, and engaging in physical activities.

Our results indicate that working long (50+) hours per week has a small negative effect on self-reported health and slightly increases the probability of high blood pressure. Long work hours have diverse impacts on different aspects of individual lifestyles, yet magnitudes are small, and we find no significant relationship between long work hours and obesity. Overall, our results provide limited evidence that long work hours in China are seriously affecting health or lifestyles. The general conclusion of our analysis is that long work hours do not seem to have any strong effects on several commonly used subjective or objective measures of health. Nor do our results provide any evidence that long work hours significantly influence diets, physical activity, or sleep time. This contrasts strongly with existing evidence in western countries; and indicates that the "long work hours culture" in China may mitigate adverse health effects of long hours. 


\section{Long Work Hours and Health in China}

\section{Introduction}

China's long weekly work hours, among the longest in the world, have given rise to substantial concerns about the negative effects such a work week may have on workers' health (Mishra \& Smyth, 2013). In a recent survey of Chinese workers, for example, respondents pointed to long work hours as one of three major reasons for health problems (Tang, 2013). Some therefore argue that the unprecedented economic growth in China may have taken place on the back of employees working long hours (Smyth, Qian, Nielsen, \& Kaempfer, 2013). As stated by Kingston (cited in Oster, 2014), due to the Confucian belief in total dedication, Chinese employers are prone to overburden their employees. At the same time, the Chinese phenomenon of "Guolaosi" (death by overwork) has received widespread attention in the Chinese media. ${ }^{1}$ For instance, a report in the prominent nationwide China Youth Daily claims that approximately 600,000 Chinese people die annually from working too hard (Monet, 2014).

There is in fact solid evidence that long work hours can be detrimental to health. For instance, according to Bannai and Tamakoshi (2014), although those who work long hours need more time to recover, a long work week restricts the amount of private time available for recovery, which can lead to exhaustion. Less private time may also give rise to irregular lifestyles and unhealthy behaviors, including lack of sleep, unhealthy diets, smoking, and alcohol consumption. Nevertheless, despite a large body of literature in several academic disciplines on the effects of long work hours on health outcomes, it remains difficult to draw clear conclusions. As several reviewers emphasize (Bannai \& Tamakoshi, 2014), results are mixed and evidence on the impact of long work hours on health remains inconclusive, not only because both "long work hours" and health outcomes are variously defined but because of the heterogeneity of individual characteristics and different uses of covariates. For China especially, the empirical evidence is extremely limited: the only three studies we are aware of (Frijters,

In Japan, this phenomenon is known as "Karoshi”. 
Johnston, \& Meng, 2009; Verité, 2004; Zhao, 2008) all use cross-sectional data and analyze only subjective (self-reported) health measures.

The purpose of this study, therefore, is to examine the impact of long work hours on health among Chinese adults aged 18-65 using data from the China Health and Nutrition Survey (CHNS) from 1991 to 2009. Our work thus makes several contributions to the literature: First, it is the most comprehensive analysis for China, where, as mentioned above, the possible negative effect of overwork is an important public health issue. Second, it fills an important research void on a research topic studied predominantly in the West, thereby providing a valuable tool for international comparison. Third, it uses a broad array of health measures, including not only measures of subjective health but also several measures of objective health (e.g., high blood pressure and obesity). Fourth, it explores several possible pathways through which long work hours could affect health. In particular, it assesses the relation between long work hours and specific lifestyles, such as time spent sleeping, preparing meals, and engaging in physical activities. Finally, and contrary to the majority of studies on this topic, it also includes a panel analysis, which allows to control for unobservable individual heterogeneity.

The general conclusion of our analysis is that long work hours do not seem to have any strong effects on several commonly used subjective or objective measures of health. Nor do our results provide any evidence that long work hours significantly influence diets, physical activity, or sleep time.

The remainder of the paper is structured as follows: Section 2 reviews the related literature. Section 3 describes our data and methodologies. Section 4 reports the results, and Section 5 concludes the paper.

\section{Prior Literature}

\section{Long work hours and subjective health}

One early meta-analysis (Sparks, Cooper, Fried, \& Shirom, 1997) of 19 studies on work hours and health provides seemingly clear evidence that long work hours have an adverse effect on self-reported health. Nevertheless, the mean correlation between 
overall health (including physiological and psychological health) and work hours is only 0.130 for physiological health 0.064 and 0.147 for psychological health, suggesting that the association between work hours and self-reported health is far from strong. Another systematic review based on 27 selected psychological and medical studies (van der Hulst, 2003) points out that 13 of these studies on the relation between long (40+ weekly) work hours and health use only subjective health measures, including general health, psychological health, physical health, and fatigue. This review finds a strong positive association between long work hours and physical health (somatic, psychosomatic symptoms, and physical strain) but no association with certain aspects of psychological health, including depression, tension/anger, and suicide. A more recent overview based on 19 studies (Bannai \& Tamakoshi, 2014) shows that long work hours $(40+$ weekly or $8+$ per day) have a negative association with sleep conditions and also diabetes mellitus (DM) when the latter is proxied by self-reported hypoglycemic medication use. Long work hours are also associated with a higher risk of depression and anxiety symptoms.

Of particular interest to our study is the research on work hours and health in Japan and South Korea, both of which have long work weeks like China (Mishra \& Smyth, 2013). For Japan, one examination of how work hours influence the biologic functions of 71 Japanese salesmen aged 22-60 (Iwasaki, Sasaki, Oka, \& Hisanaga, 1998), for instance, finds little evidence of significant differences between short and long work hours in the probability of self-reported fatigue (a feeling of local physical abnormality). However, another study based on a cross-sectional dataset of 377 Japanese workers (Nishikitani, Nakao, Karita, Nomura, \& Yano, 2005) suggests that overtime has a significant positive correlation with self-rated mental health - as measured by the Hamilton Depression Scale (HDS) and Profile of Mood State (POMS) anger-hostility scores - among both men and women. Nonetheless, once age is adjusted for, overtime work is not significantly associated with self-rated mental health measures. A survey of 843 Japanese male day workers under 60 years, in contrast, indicates that working more than 260 hours per month does have a detrimental effect on subjective depression status (Nagashima et al., 2007).

For Korea, based on a field survey of 238 male engineers aged 22-46 in South Korea, Park et al. (2001) identify a significant association between weekly work hours and subjective stress response and fatigue complaints before work. Using the same dataset, 
Park, Kim, Chung, and Hisanaga (2001) find that respondents working more than 60 hours per week are more likely than those working fewer hours to suffer from subjective fatigue complaints. Using the 2006 First Korean Working Conditions Survey, Park, Yi, and Kim (2010) also find that working over 60 hours per week is associated with a pronounced increase in stress, especially for males, in comparison to working less than 40 hours per week.

We know of only three studies that analyze the effect of work hours on subjective health in China. ${ }^{2}$ The first, based on a survey of 768 workers at 40 export factories in southern China (Verité, 2004), does associate long work hours with self-reported fatigue, exhaustion, sadness, and depression. ${ }^{3}$ Likewise the second, based on data from the 2008 Urban Migrant Survey covering 3,143 urban migrant workers, shows that working over 60 hours per week has an adverse effect on self-reported mental health (Frijters, Johnston, \& Meng, 2009). ${ }^{4}$ A third study by Zhao (2008) using 2000 CHNS data, however, assesses all the effects of work hours on self-rated health as insignificant. ${ }^{5}$

\section{Long work hours and objective health}

As regards objectively measured health, the review by Sparks, Cooper, Fried, and Shirom (1997) finds that long work hours have detrimental effects on coronary heart disease (CHD), cardiovascular problems, and stress levels. However, van der Hulst (2003) documents mixed results: long work hours seemingly have positive effects on cardiovascular disease, diabetes, disability retirement, and fasting blood sugar but negative effects on hypertension, sickness absence, immunity, and noradrenaline ( $p$. 179). Bannai and Tamakoshi's (2014) overview, on the other hand, identifies no association between long work hours and blood pressure or type $2 \mathrm{DM}$.

2 In a study on the relation between overtime and psychological well-being among 130 full-time office workers aged 23-44 in a branch of a Chinese information and communication technology company, Houdmont, Zhou, and Hassard (2011) find that high-level overtime ( $\geq 15$ hours/week) has lower levels of psychological well-being than low-level overtime (14 hours/week).

3 The 40 factories selected are mainly in the garment, shoe, and knitting industries located in Guangdong, Fujian, Jiangsu, and Zhejiang provinces. The results also indicate, however, that no association exists between long work hours and the risk of occupational accidents (Verité, 2004).

4 The dependent variables are a binary variable for whether or not the individual works at least 60 hours per week and a continuous variable for actual weekly work hours.

5 Zhao (2008) focuses on the determinants of self-reported health status in China, identifying education, region, gender, marital status, and individual body weight as important health factors in China. He also identifies a nonlinear relation between age and health. It should be noted, however, that he provides no clear explanation of how "long work hours" is defined in his study. 
In Japan of the late 1970s, when Uehata (1978) started to investigate 17 Karoshi cases (i.e., death or permanent disability resulting from cardiac and cerebral infarction caused by overwork), the danger of death due to overwork was brought to light and gained expanding attention as the number of employees faced with long work hours increased substantially during the following decades. Karoshi not only became a serious social problem, but was recognized as an official cause of occupational death for which surviving workers and the families of the victims can claim government compensation (see Iwasaki, Takahashi, \& Nakata, 2006). In another case study, Uehata (1991) reviewed 203 middle-aged Karoshi victims who had been affected by cardiovascular attacks and for whom such compensation was claimed. Two thirds of these victims under study - mostly male workers - had been exposed to excessive workload including extremely long working hours of more than 60 hours per week, an accumulation of more than 50 hours of overtime in a month, and holiday work previous to the heart attack. The relationship between excessively long work hours and an increased risk of myocardial infarction is confirmed in a case-control study by Liu and Tanaka (2002). In this study, 260 Japanese men aged between 40 and 79 admitted to hospitals due to acute myocardial infarction are matched with respect to age and residence with a control group of 445 men exempt from acute myocardial infarction. The authors show that working excessive overtime, i.e. working more than 60 hours per week doubles the risk of acute myocardiac infarction compared to 40 and less weekly work hours. Moreover, insufficient sleep (less than 5 hours per day or 2 or more days per week with less than 5 hours of sleep) is also associated with a two- to threefold risk of cardiac infarction.

Likewise, Iwasaki, Sasaki, Oka, and Hisanaga (1998) find a significant association between long work hours among salesmen aged 50-60 and a higher risk of systolic blood pressure (SBP), while Hayashi, Kobayashi, Yamaoka, and Yano (1996) show that 24-hour average blood pressure is higher among male white-collar employees who work overtime. Similarly, Nakanishi et al. (2001) conclude that long work hours has a negative impact on the risk of hypertension in male white-collar workers aged 35-54. Wada et al. (2006) also confirm that workers with average monthly overtime above 50 hours have lower risks of developing hypertension. ${ }^{6}$ For male engineers in South Korea, Park et al. (2001) report that long work hours increase urinary adrenaline levels and decrease low frequency heart rate variability. A recent study of 322 male patients aged

6 Hypertension is defined as $\mathrm{SBP} \geq 140 \mathrm{~mm} \mathrm{Hg}$ or $\mathrm{DBP} \geq 90 \mathrm{~mm} \mathrm{Hg}$ (Wada et al., 2006). 
23-60 in Taiwan (Cheng et al., 2014), however, shows that working 60+ hours per week (versus 40-48 hours), significantly increases the risk for CHD.

\section{Long work hours and individual lifestyles}

Van der Hulst (2003) summarizes the influence of long work hours on health-related behaviors as follows: in general, they have a weak but positive effect on smoking and unhealthy eating habits, no effect on psychotropic drug use and physical exercise, but a negative effect on sleep hours. The effects of long work hours on obesity measures, however, are mixed, showing a positive association with body mass index (BMI) but no association with skinfold thickness. Bannai and Tamakoshi (2014) also find no association between long work hours and such health-related behaviors as alcohol consumption, smoking, weight gain, and physical activity. ${ }^{7}$ Nevertheless, a study of 3870 division/section heads and 2666 foremen in Japan (Maruyama \& Morimoto, 1996) shows that working over 10 hours per day significantly influences the managers' lifestyle, including sleep patterns and diets. There is also a higher prevalence of smokers and frequent drinkers among the foremen who work long hours.

In terms of health behaviors, a study of male Americans aged 25-55 suggests that longer work hours are negatively correlated with participation in physical activity $(\mathrm{Xu}, 2013),{ }^{8}$ while a quasi-experiment that exploits the effect of work hours on health and health behaviors in France finds that a decline in work hours is correlated with a decrease in the probability of smoking, alcohol consumption, and also physical inactivity (Berniell, 2012). This latter study solves the work hours endogeneity problem by using a differences-in-differences strategy (DID) and an instrumental variables approach (IV) and thus captures the short-term rather than the long-term effects of work hours. ${ }^{9}$

Overall, a number of aspects of past research are worth emphasizing: First, the empirical results suggest that long work hours negatively affect health measured by

Based on an sample of 3830 adults age 25-54 from the data of the National Population Health Survey in Canada, Shields (1999) provides interesting evidence that long work hours (41-59 hours per week) have no significant association with physical activity in comparison to standard working hours (35-40 hours per week).

8 Measured with a binary variable equal to 1 if the respondent reported any physical activity or exercises in the previous 30 days ( $\mathrm{Xu}, 2013)$.

9 For smoking and BMI, outcome data are available for both the pre- and post-treatment periods, so for these variables, the authors apply a DID approach; for alcohol consumption and physical activity, however, information is only accessible for the post-treatment period, so they adopt an IV method. This study also suggests that there is no association between a reduction in work hours and health status as represented by self-reported health and an index of vital risk (Berniell, 2012). 
some indicators like depressive state, anxiety, coronary heart disease, self-reported physical health and fatigue (see Bannai \& Tamakoshi, 2014; van der Hulst, 2003). Second, the association of long work hours with lifestyle is ambiguous except for sleep, for which the findings are quite robust, with an increase in the length of the work week being clearly associated with less sleep time (van der Hulst, 2003). In addition, information on the paths through which long work hours affect health is scant, except for the general causal pathway described by Bannai and Tamakoshi (2014), who outline why long work hours result in health problems. Furthermore, a major drawback in most studies, as van der Hulst (2003) emphasizes, is their cross-sectional design. Studies on associations between long work hours and subjective health are the most common, and only a limited number of studies use both subjective and objective measures of health. Such weakness especially holds for the three studies for China (Frijters, Johnston, \& Meng, 2009; Verité, 2004; Zhao, 2008). In these studies, various subjective health outcomes (self-reported fatigue, exhaustions, sadness, depression, general mental problem and self-reported health) are used and positive associations with work time can be observed - especially with regards to self-reported fatigue, exhaustion, sadness and depression (Verité, 2004) and mental health problems (Frijters, Johnston, \& Meng, 2009). However, no association is found between work time and the increased risk of accidents (Verité, 2004) or self-reported health status (Zhao, 2008). Finally, existing literature on long work hours and health is strongly dominated by research in Western countries and Japan, thereby making generalizations for countries such as China difficult.

To remedy some of these shortcomings, we perform a longitudinal analysis of CHNS data to identify the effects of long work hours on both subjective and objective measures of health among Chinese workers. The CHNS also allows us to investigate possible pathways through which long work hours may influence health. 


\section{Data and Methodology}

\section{Survey and sample}

The China Health and Nutrition Survey (CHNS) currently encompasses 9 waves collected in 1989, 1991, 1993, 1997, 2000, 2004, 2006, 2009, and 2011. ${ }^{10}$ The survey is administered to 5884 households, containing 27447 individuals, in 9 Chinese provinces (Liaoning, Heilongjiang, ${ }^{11}$ Jiangsu, Shandong, Henan, Hubei, Hunan, Guangxi, and Guizhou). The multistage random cluster design of this unique largescale longitudinal dataset successfully captures the substantial spatiotemporal variation in the social, economic, and health dimensions of the Chinese population.

In this study, we use a mostly unbalanced panel for 1991 to 2009. Specifically, we analyze employed individuals aged 18 to 65 and exclude respondents who report working less than 11 hours per week in order to avoid a "healthy worker effect", i.e., we exclude workers who might choose very short work hours because of adverse health conditions like high blood pressure or cardiovascular disease (Yang, Schnall, Jauregui, $\mathrm{Su}, \&$ Baker, 2006). After dropping missing values for the control variables, our final sample comprises 11034 Chinese workers aged 18-65 years. Because of the limited availability of data on certain outcome variables, sample sizes vary among the analyses: specifically, 11034 observations for high blood pressure and obesity based on body mass index (1991-2009), 8793 observations for obesity based on waist circumference (1993-2009), 5300 observations for self-reported health (1997-2006), 4215 observations for daily sleep time (2004-2009), 10933 observations for calorie and fat intakes (1991-2009), 4082 observations for time spend on preparation and cooking (1991-2009), 6822 observations for physical activity (1997-2009), 4055 observations for time spend on watching TV (2004-2009) and 2096 observations for time spend on reading, writing and drawing (2004-2009).

\section{Work hours}

Weekly work hours (WH) are measured by the question "how many hours did you work during the past week?" As in Frijters, Johnston, and Meng (2009), we integrate WH into the model in two ways: First, we include WH dummy variables by recoding work

For further information on the CHNS, see Zhang, Zhai, Du, and Popkin (2014).

11 Heilongiiang province was introduced as the ninth province in 1997. 
hours into four categories: $11 \leq \mathrm{WH} \leq 30,31 \leq \mathrm{WH} \leq 40,41 \leq \mathrm{WH} \leq 50$ and $\mathrm{WH} \geq 51$. Because 40 hours per week ( 8 hours per day) is the standard work period dictated by China's Labor Law (Casale \& Zhu, 2013), we define long work hours as more than 40 hours per week, a definition also used in several studies cited in the meta-analyses discussed above (see for instance Bannai \& Tamakoshi, 2014; van der Hulst, 2003). Furthermore, we select $31-40$ work hours per week as our reference category. It is also worth noting that using dummy variables for weekly work hours allow us to capture possible nonlinearities in the long work hours-health relation. Second, we integrate a continuous variable into our models that captures actual hours worked each week.

\section{Subjective health}

We use self-reported health (SRH) as the main measure of subjective health. It includes not only mental and physical health but also subjective experience of acute and chronic diseases and overall feelings of well-being (Xie \& Mo, 2014). In the CHNS, SRH is measured on a 4-point scale based on the following question: ${ }^{12}$ "Right now, how would you describe your health compared to that of other people in your age? 1=bad; $2=$ fair; 3=good; 4=excellent." These data are only available for 1997 to 2006.

\section{Objective health}

As in several past studies, we use obesity and hypertension measures to capture objective measures of health. In the CHNS, blood pressure measurements are taken three times by a health professional using a mercury sphygmomanometer, with a time interval between successive pairs of measures of at least 1 minute (Lei, Yin, \& Zhao, 2012). We calculate the mean values of systolic blood pressure (SBP) and diastolic blood pressure (DBP) based on the second and third measurements to avoid potential measurement biases. ${ }^{13}$ Following most of the existing literature (see for example Lei, Yin, \& Zhao, 2012), we define high blood pressure as a binary variable equal to 1 if the respondent's $\mathrm{SBP} \geq 140 \mathrm{~mm} \mathrm{Hg}$ or $\mathrm{DBP} \geq 90 \mathrm{~mm} \mathrm{Hg}$ or the respondent is taking antihypertension medication, 0 otherwise.

We assess obesity using both body mass index (BMI) and waist circumference (WC). First, general obesity using BMI is assessed on a scale ranging from 0 to 3 , which is

12 We do not employ other measures of self-rated chronic diseases available in CHNS (i.e., diabetes, myocardial infarction, apoplexy, or asthma) because their prevalence in our sample is very small: $1.27 \%$ for diabetes, $0.22 \%$ for myocardial infarction, $0.16 \%$ for apoplexy, and $0.66 \%$ for asthma.

13 A detailed description of blood pressure measurement is available in Lei, Yin, and Zhao (2012). 
based on the following criteria of the Working Group on Obesity in China (WGOC) (Zhou \& Cooperative Meta-Analysis Group of the Working Group on Obesity in China, 2002): $0=$ underweight if $\mathrm{BMI}<18.5,1=$ normal weight if $18.5 \leq \mathrm{BMI}<24,2=$ overweight if $24 \leq \mathrm{BMI}<28$, and $3=$ obese if $\mathrm{BMI} \geq 28$. Central obesity is dichotomized as 1 given a $\mathrm{WC} \geq 85 \mathrm{~cm}$ for men and $\mathrm{WC} \geq 80 \mathrm{~cm}$ for women, 0 otherwise.

\section{Individual lifestyles}

Because individual lifestyles, particularly unhealthy behaviors, may be associated with long work hours (see for example Artazcoz, Cortes, Escriba-Aguir, Cascant, \& Villegas, 2009), we analyze three aspects likely to be affected: daily sleep time, diet (calorie and fat intake, ${ }^{14}$ and time spent on food preparation and cooking), and physical activity (sports and sedentary activities). Individual sleep time per day is measured by the following question: "How many hours each day do you usually sleep, including daytime and nighttime?" Calorie intake is defined as the 3-day average intake in kilocalories, while fat intake is a 3-day mean value in grams. In the CHNS, all respondents are asked directly about all food consumed inside and outside the home, and food items, types of meals, and places of food consumption on the preceding day are recoded (Batis et al., 2014). The time (in hours) spent on food preparation and cooking in the household is assessed as follows: "How much time did you spend per day, on average, cooking and preparing meals?"

For physical activities, we create a dichotomous variable having a value of 1 if the respondent participates in sports, including martial arts, gymnastics, track and field/swimming, ball sports (e.g., soccer, basketball, or tennis), other sports (e.g., ping pong or tai chi), and 0 otherwise. We define sedentary activity as the number of hours per week spent watching TV, reading (e.g., books, newspapers, or magazines), writing, or drawing. Lastly, we categorize the independent variables in our analysis into three subgroups: individual, family, and community characteristics.

\section{Individual characteristics}

Individual controls include gender, marital status, education levels, activity levels, health insurance, risky behaviors (smoking, heavy drinking, and obesity), residency

14 Excessive fat intake and insufficient physical activity can result in higher risks for some chronic diseases, including hypertension and diabetes (Ministries of Health and Science and Technology \& the National Bureau of Statistics of the Peoples Republic of China, 2004). 
area, and work conditions. The gender dummy equals 1 if the respondent is male, 0 otherwise. Marital status is a binary variable equal to 1 for the married, 0 otherwise. Education is measured on a 6 -point scale: $0=$ illiterate, $1=$ primary school, $2=$ middle school, $3=$ high school, $4=$ technical school, and 5=university or higher. We recode it as dummies with illiterate as the reference group. Activity levels are grouped into five categories: $0=$ very light, $1=$ light, $2=$ moderate, $3=$ heavy, and $4=$ very heavy. Individual medical insurance is a dichotomous variable equal to 1 if medical insurance is available for the respondent, 0 otherwise. Residency area is a dummy variable equal to 1 if the respondent lives in an urban area, 0 otherwise.

Working conditions include translog average monthly wage (including subsidies) in the past year and dummy variables for formal employment and types of work unit. Specifically, formal employment is a dummy variable equal to 1 if the respondent works for another person or enterprise as a permanent employee and to 0 if the respondent is self-employed, a temporary worker, or a paid family worker (Chen \& Hamori, 2013). Work units are grouped into 8 classes: $0=$ three-capital enterprise (ownership shared by foreigners, overseas Chinese, and joint venture), 1=government, $2=$ state service or institute, $3=$ state-owned enterprise, $4=$ small collective enterprise, $5=$ large collective enterprise, $6=$ family contract farming, and $7=$ private or individual enterprise.

Smoking is classified according to the number of cigarettes smoked per day (NCS): $0=$ nonsmoker, $1=1 \leq \mathrm{NCS} \leq 10,2=11 \leq \mathrm{NCS} \leq 20$, and $3=\mathrm{NCS}>20$. Heavy drinking is defined by a binary variable equal to 1 if alcohol is consumed three or more times per week, 0 otherwise. Obesity is defined as explained above.

\section{Family characteristics}

Family controls include translog household income and household size. We also introduce the availability of safe drinking water, sanitation, and electricity in the household, because they might also affect individual health status. The safe drinking water variable equals 1 if the household's drinking water source is a water plant or ground water more than 5 meters deep, 0 otherwise. The sanitation variable equals 1 if the household can access in-house or outside flushing toilet facilities, 0 otherwise. The electricity variable equals 1 if electric facilities are available for the household, 0 otherwise. 


\section{Community characteristics}

The presence of health facilities in the community is captured by a dummy variable that equals 1 if a health facility is located in the village/neighborhood and 0 if in another village/town/city or in the respondent's city but in a different neighborhood. The distance to the health facility is a continuous variable measured in kilometers.

\section{Estimation approaches}

To examine the cross-sectional association between long work hours and high blood pressure, we use a probit regression model of the following form:

$$
H B P_{i}=\alpha_{0}+\alpha_{1} W H_{i}+\alpha_{2} I_{i}+\alpha_{3} F+\alpha_{4} C+\alpha_{5} Y+\alpha_{6} P+\varepsilon_{i}
$$

where $H B P_{i}$ is a binary variable denoting high blood pressure of individual $i$, and $W H_{i}$ designates dummies for weekly work hour category or actual weekly work hours of individual $i . I_{i}$ is a vector of individual $i$ 's characteristics, $F$ is a vector of family characteristics, and $C$ is a vector of community characteristics. $Y$ is a vector of year dummy variables (with 1991 as the reference year), and $P$ is a vector of provincial dummy variables (with Liaoning as the reference province). $\varepsilon_{i}$ is the error term and $\alpha_{1}$ is the key coefficient of interest.

To analyze the impact of long work hours on obesity using waist circumference (measured as a binary variable), we use the same specification as in equation (1). Likewise, because SRH and BMI-based obesity are both measured on a 4-point scale, we estimate the impact of long work hours on these variables using an ordered probit model, whose specification is also similar to equation (1).

Because of potential biases from individual time-invariant unobservables, we investigate the association between long work hours and high blood pressure by estimating the following fixed-effects logit model:

$$
H B P_{i t}=\alpha_{1} W H_{i t}+\alpha_{2} G_{i t}+\mu_{i}+\varepsilon_{i t} i=1, \cdots, N ; t=1, \cdots, T
$$

where $H B P_{i t}$ denotes individual $i$ 's high blood pressure status at time $\mathrm{t}$, and $W H_{i t}$ is the work hour category or continuous weekly work hours of individual $i$ at time $t$. $G_{i t}$ represents a set of time-variant controls including age, translog wage, translog household income, and household size. The individual time-invariant effects are denoted by $\mu_{i}$, and $\varepsilon_{i t}$ represents the idiosyncratic error term. 
Because SRH is ordinal, we employ a fixed-effects ordered logit model of the following form:

$$
S R H_{i t}^{*}=X_{i t}^{\prime} \beta+\mu_{i}+\varepsilon_{i t}, i=1, \cdots, N ; t=1, \cdots, T
$$

where $S R H_{i t}^{*}$ is a latent variable of self-reported health for individual $i$ at time $t$, $X_{i t}$ denotes observed characteristics, and $\mu_{i}$ captures the unobserved time-invariant characteristics. The latent variable is related to the observable ordered variable as follows:

$$
S R H_{i t}=k \text { if } \tau_{k}<S R H_{i t}^{*} \leq \tau_{k+1}, k=1, \cdots, 4
$$

For these calculations, we employ a consistent estimator of the fixed-effects ordered logit model, proposed by Baetschmann, Staub, and Winkelmann (2011). ${ }^{15}$ In principle, existing estimators (e.g. Chamberlain, 1980; Das \& van Soest, 1999; Ferrer-i-Carbonell \& Frijters, 2004) simplify the ordered logit model to a binary logit model as the ordered response variable is dichotomized into two categories using a certain cut-off point. The main difference of these estimators is the way the cut-off point for the dichotomization is determined. The Blow-Up and Cluster (BUC) estimator by Baetschmann, Staub, and Winkelmann (2011) estimates all possible dichotomizations jointly and uses observation-specific cut-off points. In a Monte Carlo simulation and in an application of German Socio-Economic Panel (GSOEP) data the authors show that the BUC estimator clearly outperforms the existing estimators, especially those which are based on an endogenous dichotomization where the cut-off points are determined as a function of the outcome variable. Moreover, the BUC estimator is superior if the ordered dependent variable exhibits low frequencies in certain response categories. For the sake of comparison, we also take self-reported health as a cardinal variable and estimate fixed-effects models of the following form:

$$
S R H_{i t}=\alpha_{1} W H_{i t}+\alpha_{2} Y_{i t}+\mu_{i}+\varepsilon_{i t} i=1, \cdots, N ; t=1, \cdots, T
$$

where $S R H_{i t}$ indicates individual $i$ 's self-reported health status at time $t$, and $W H_{i t}$ is the work hour category or continuous weekly work hours of individual $i$ at time $t$. $Y_{i t}$ denotes a set of time-variant controls including age, translog wage, translog

15 Stata codes for implementing the BUC estimator are available in Baetschmann, Staub, and Winkelmann (2011). This estimator, discussed in detail in Baetschmann, Staub, and Winkelmann (2011), is also used in Bell, Otterbach, and Sousa-Poza (2012) in their analysis of working hours constraints and health. 
household income and household size. The individual time-invariant effects are captured by $\mu_{i}$, and $\varepsilon_{i t}$ represents the disturbance error.

To detect the possible impact of long work hours on individual lifestyles, we use an ordinary least square (OLS) estimation as follows:

$$
L S_{i}=\beta_{0}+\beta_{1} W H_{i}+\beta_{2} I_{i}+\beta_{3} F+\beta_{4} C+\beta_{5} Y+\beta_{6} P+\varepsilon_{i}
$$

where $L S_{i}$ is our measure for individual $i$ 's lifestyles, including daily sleep time, diet (e.g. calorie and fat intakes, time spend on food preparation and cooking), and sedentary activities (e.g. time spend on watching TV, reading, writing and drawing), and $W H_{i}$ denotes dummies for weekly work hour category or actual weekly work hours of individual $i . I_{i}$ is a vector of individual $i$ 's characteristics, $F$ is a vector of family characteristics, and $C$ is a vector of community characteristics. $Y$ is a vector of year dummy variables (with 1991 as the reference year for calorie/fat intakes and time spent cooking and with 2004 as the reference year for sedentary activities), and $P$ is a vector of provincial dummy variables (with Liaoning as the reference province). $\varepsilon_{i}$ is the error term and $\beta_{1}$ is the key coefficient of interest. Additionally, we investigate the impact of long work hours on sports participation (measured as a dichotomous variable) using a probit estimation and adopt the similar specification to equation (6).

\section{Results}

\section{Descriptive statistics}

Descriptive statistics are presented in Appendix Table A1, which shows that the average age of the workers in our sample is nearly 39 , with males accounting for slightly more than half the sample. The average work week is about 47 hours, with around $62 \%$ of respondents working more than the national standard of 40 hours per week. Fifteen percent of our sample has high blood pressure, and based on the WGOC criteria, approximately $26.5 \%$ are overweight, $6.4 \%$ are obese when BMI proxies for general obesity are used, and around $24.3 \%$ are obese when WC is used (see Table A2 of the Appendix). Additionally, the distribution as well as the trend of weekly work hours from 1991 to 2009 are illustrated in Fig. A1 in the Appendix. Two points are worth noting: First, the peak of weekly work hours has shifted significantly to the left, with the modus declining from 48 to 40 hours per week. This is especially the case after 
1993, which might be a result of the impact of 1995 Labor Regulations (which reduced weekly work hours from 44 to 40; see Casale \& Zhu, 2013). Second, the distribution of weekly work hours has become flatter and dispersion is larger, indicating that the trend observed in Western countries of more heterogeneous work-time arrangements appears to be setting in. We also show the changes of various measures of health from 1991 to 2009 in Table A2 of the Appendix. ${ }^{16}$ Overall, we observe an increasing trend in the prevalence of high blood pressure and obesity. The average daily sleep time is around 7.89 hours, and the 3-day average calorie and fat intakes are approximately $2393 \mathrm{kcal}$ and 81 grams, respectively.

\section{WH and $S R H$}

As regards the association between long work hours and SRH (see Table 1), once confounders are controlled for, relative to a 31-40 hour work week, only working 4150 hours a week is significantly and negatively associated with SRH (columns 2-4). ${ }^{17}$ Interestingly, however, the coefficient for very long work hours (over 50 per week) is insignificant. The results using actual work hours are also insignificant once control variables are included (columns 6-9). These findings are in line with those of Zhao (2008).

According to the panel analysis results in Table 2, relative to working 31-40 hours weekly, working 41-50 hours has a significant but negative impact on SRH irrespective of whether a fixed-effects or fixed-effects ordered logit model is used (see columns 1 and 2). However, when employing the continuous variable, we find no significant association between actual work hours and SRH. Although the results in Table 2 indicate that long work hours do indeed have a negative effect on SRH, as perhaps best shown in column (1), the effect is relatively small $(-0.12$ on a 4-point scale).

16 Regarding Table A2 in the Appendix, although the results are based on WGOC criteria, the prevalence of overweight, general obesity and abdominal obesity are comparable to the results from Xi et al. (2012) based on the criteria from the World Health Organization.

17 We also note that males have better health than females, which echoes the results observed in Zhao (2008). In addition, household income is an important predictor of good health. 


\section{Table 1}

Ordered probit model estimates for self-reported health: 1997-2006.

Source: China Health and Nutrition Survey 1997, 2000, 2004, 2006.

\begin{tabular}{lccccccccc}
\hline Variables & $(1)$ & $(2)$ & $(3)$ & $(4)$ & $(5)$ & $(6)$ & $(7)$ & $(8)$ & $(9)$ \\
\hline $11 \leq \mathrm{WH} \leq 30$ & -0.105 & -0.098 & -0.094 & -0.095 & & & & & \\
& $(0.064)$ & $(0.069)$ & $(0.069)$ & $(0.070)$ & & & & & \\
$41 \leq \mathrm{WH} \leq 50$ & 0.015 & $-0.108^{* *}$ & $-0.114^{* *}$ & $-0.115^{* * *}$ & & & & & \\
& $(0.041)$ & $(0.044)$ & $(0.044)$ & $(0.045)$ & & & & & \\
$\mathrm{WH} \geq 51$ & $0.094^{* *}$ & -0.054 & -0.053 & -0.057 & & & & & \\
& $(0.038)$ & $(0.047)$ & $(0.047)$ & $(0.047)$ & & & & & \\
$\mathrm{WH}$ & & & & & $0.003^{* *}$ & -0.001 & -0.001 & -0.001 & 0.002 \\
& & & & & $(0.001)$ & $(0.001)$ & $(0.001)$ & $(0.001)$ & $(0.002)$ \\
\hline$N$ & 5300 & 5300 & 5300 & 5300 & 5300 & 5300 & 5300 & 5300 & 2233 \\
Pseudo $R^{2}$ & 0.001 & 0.051 & 0.053 & 0.056 & 0.0004 & 0.051 & 0.052 & 0.056 & 0.069 \\
\hline
\end{tabular}

The dependent variable is self-reported health measured on a 4-point scale ( $0=$ poor, $1=$ fair, $2=$ good, $3=$ excellent $)$; $\mathrm{WH}=$ weekly work hours. Specifications (1)-(4) include work hour dummies (with $31 \leq \mathrm{WH} \leq 40$ as the reference); (2)-(4) also include individual characteristics, family characteristics, provincial dummies (with Liaoning as the reference), and year dummies (with 1997 as the reference); (3) further adds in the characteristics of health facilities in the community and (4) adds in risk behaviors (obesity, smoking, and heavy drinking); (5)-(9) include actual weekly work hours, with (9) only including employees who work 41 hours per week or more. Specification (6) includes the same controls as (2), (7) includes the same controls as (3), and (8) and (9) include the same controls as (4). Robust standard errors are in parentheses; ${ }^{*} p<0.1,{ }^{* *} p<0.05,{ }^{* * *} p<0.01$.

Table 2

Fixed-effects estimates of self-reported health: 1997-2006.

Source: China Health and Nutrition Survey 1997, 2000, 2004, 2006.

\begin{tabular}{|c|c|c|c|c|c|}
\hline \multirow{4}{*}{ Variables } & \multicolumn{2}{|c|}{ WH dummies } & \multicolumn{3}{|c|}{ Actual WH } \\
\hline & $(1)$ & $(2)$ & $(3)$ & $(4)$ & $(5)$ \\
\hline & Fixed-effects & Fixed-effects & Fixed-effects & Fixed-effects & Fixed-effects \\
\hline & & ordered logit & & ordered logit & ordered logit \\
\hline \multirow[t]{2}{*}{$11 \leq \mathrm{WH} \leq 30$} & -0.115 & -0.250 & & & \\
\hline & $(0.096)$ & $(0.221)$ & & & \\
\hline \multirow[t]{2}{*}{$41 \leq \mathrm{WH} \leq 50$} & $-0.120^{* *}$ & $-0.235^{*}$ & & & \\
\hline & $(0.054)$ & $(0.124)$ & & & \\
\hline \multirow[t]{2}{*}{$\mathrm{WH} \geq 51$} & -0.094 & $-0.235^{*}$ & & & \\
\hline & $(0.064)$ & $(0.132)$ & & & \\
\hline \multirow[t]{2}{*}{ WH } & & & -0.002 & -0.006 & -0.011 \\
\hline & & & $(0.002)$ & $(0.005)$ & $(0.009)$ \\
\hline Observations & 3092 & 6810 & 3092 & 6810 & 1974 \\
\hline$R^{2}$ & 0.019 & - & 0.015 & - & - \\
\hline \multicolumn{6}{|c|}{$\begin{array}{l}\text { The dependent variable is self-reported health measured on a } 4 \text {-point scale ( } 1=\text { poor, } 2=\text { fair, } 3=\text { good, } 4=\text { excellent); } \\
\text { WH =weekly work hours. Specifications (1) and ( } 2 \text { ) include work hours dummies (with } 31 \leq \mathrm{WH} \leq 40 \text { as the reference); } \\
\text { (3)-(5) include weekly work hours, with (5) only including employees who work } 41 \text { hours per week or more. In (1)- } \\
\text { (5), the controls are translog wage, age, translog household income, and household size. For (1) and ( } 3 \text { ), community- } \\
\text { level clustered standard errors are in parentheses; }{ }^{*} p<0.1,{ }^{*} p<0.05, * * * p<0.01 \text {. }\end{array}$} \\
\hline
\end{tabular}




\section{WH and high blood pressure}

Table 3 shows the probit estimates of the impact of long work hours on high blood pressure. Taking weekly work hours between 31 and 40 as the reference category, we find that working more than 50 hours per week significantly increase the probability of high blood pressure, although the magnitudes are relatively small. ${ }^{18}$ This finding is consistent with those of Yang et al. (2006) for a sample of Californian workers. We also calculate the average marginal effects of weekly work hours (from 11 to 70) on high blood pressure, showing that the probability of high blood pressure increases as the weekly work hours increase, with marginal effects ranging from 0.134 to 0.162 (see Fig. A2 in the Appendix). It is important, however, to highlight that the confidence intervals are relatively wide, suggesting that the uncertainty might be greater. For actual weekly work hours, however (as captured by our continuous variable), we observe no signification association between long work hours and the probability of high blood pressure (see column 9).

\section{Table 3}

Probit model estimates for high blood pressure: 1991-2009.

Source: China Health and Nutrition Survey 1991, 1993, 1997, 2000, 2004, 2006, and 2009.

\begin{tabular}{lccccccccc}
\hline Variables & $(1)$ & $(2)$ & $(3)$ & $(4)$ & $(5)$ & $(6)$ & $(7)$ & $(8)$ & $(9)$ \\
\hline $11 \leq \mathrm{WH} \leq 30$ & 0.083 & 0.068 & 0.067 & 0.056 & & & & & \\
& $(0.063)$ & $(0.071)$ & $(0.071)$ & $(0.072)$ & & & & & \\
$41 \leq \mathrm{WH} \leq 50$ & $-0.109^{* * *}$ & 0.064 & 0.062 & 0.072 & & & & & \\
& $(0.035)$ & $(0.047)$ & $(0.047)$ & $(0.048)$ & & & & & \\
$\mathrm{WH} \geq 51$ & $0.110^{* * *}$ & $0.142^{* * *}$ & $0.143^{* * *}$ & $0.152^{* * *}$ & & & & & \\
& $(0.039)$ & $(0.050)$ & $(0.050)$ & $(0.051)$ & & & & & \\
$\mathrm{WH}$ & & & & & $0.002^{*}$ & 0.002 & 0.002 & $0.002^{*}$ & 0.0004 \\
& & & & & $(0.001)$ & $(0.001)$ & $(0.001)$ & $(0.001)$ & $(0.002)$ \\
\hline$N$ & 11034 & 11034 & 11034 & 11034 & 11034 & 11034 & 11034 & 11034 & 6844 \\
Pseudo $R^{2}$ & 0.004 & 0.126 & 0.126 & 0.164 & 0.0004 & 0.125 & 0.126 & 0.164 & 0.175 \\
\hline
\end{tabular}

The dependent variable is a binary dummy for high blood pressure; $\mathrm{WH}=$ weekly work hours. Specifications (1)-(4) include the work hour dummies (with $31 \leq \mathrm{WH} \leq 40$ as the reference); (2)-(4) also include individual characteristics, family characteristics, provincial dummies (with Liaoning as the reference), and year dummies (with 1991 as the reference); (3) further includes the characteristics of health facilities in the community, and (4) adds in risk behaviors (obesity, smoking, and heavy drinking). Specifications (5)-(9) include actual weekly work hours, with (9) only including employees who work 41 hours per week or more.; (6) includes the same controls as (2), (7) includes the same controls as (3), and (8) and (9) include the same controls as (4). Robust standard errors are in parentheses; ${ }^{*} p<$ $0.1,{ }^{* *} p<0.05,{ }^{* * *} p<0.01$.

18 Results for other covariates included in the regressions but not reported here show that respondent age is uniformly and significantly positively correlated with the probability of high blood pressure. Moreover, obesity and overweight are major contributing factors to an increase in this probability. 
In all the specifications for the fixed-effects logit estimates (which rely on a much smaller sample size), the odds ratios indicate no significant association between long work hours and high blood pressure (see Table 4). Individual heterogeneity could thus be driving the significant results in Table 3, although the small (and different) samples make drawing such a conclusion difficult.

\section{Table 4}

Fixed effects logit estimates of high blood pressure: 1991-2009.

Source: China Health and Nutrition Survey 1991, 1993, 1997, 2000, 2004, 2006, and 2009.

\begin{tabular}{|c|c|c|c|}
\hline Variables & $\begin{array}{c}(1) \\
\text { WH dummies }\end{array}$ & $\begin{array}{c}\text { (2) } \\
\text { Actual WH }\end{array}$ & $\begin{array}{c}(3) \\
\text { Actual WH }(\geq 41)\end{array}$ \\
\hline $11 \leq \mathrm{WH} \leq 30$ & $\begin{array}{c}0.842 \\
(0.219)\end{array}$ & & \\
\hline $41 \leq \mathrm{WH} \leq 50$ & $\begin{array}{c}0.919 \\
(0.140)\end{array}$ & & \\
\hline $\mathrm{WH} \geq 51$ & $\begin{array}{c}1.272 \\
(0.225)\end{array}$ & & \\
\hline WH & & $\begin{array}{c}1.005 \\
(0.005)\end{array}$ & $\begin{array}{c}1.013 \\
(0.010)\end{array}$ \\
\hline Observations & 1965 & 1965 & 887 \\
\hline
\end{tabular}

As a robustness check, we also separately explore the influence of long work hours on systolic blood pressure (SBP) and diastolic blood pressure (DBP). As Table A3 in the Appendix shows, relative to the reference category of 31-40 hours, working over 50 hours per week has a significant and positive impact on both SBP and DBP (see columns 1 and 4). These results not only conform to those in Table 3 but are in line with Iwasaki, Sasaki, Oka, and Hisanaga (1998, p. 364) finding that the SBP of 50- to 60 -year-old Japanese salesmen working long hours is significantly higher than that of colleagues working shorter hours. ${ }^{19}$

19 To shed light on the association between long work hours and cardiometabolic risks in general (diabetes, dyslipidaemia, hypertension, and inflammation), we analyze biomarker data from the CHNS, which, however, are only available for 2009 and for quite a small sample. Specifically, we create binary variables for prediabetes, diabetes, dyslipidaemia, and inflammation, and then, following Yan et al. (2012) and Ning and Bloomgarden (2013), define the prediabetes dummy as a dichotomous variable equal to 1 if total glucose is $\geq 100 \mathrm{mg} / \mathrm{dL}$ and $<126 \mathrm{mg} / \mathrm{dL}$, and 0 otherwise. Likewise, the diabetes dummy equals 1 if total glucose is $\geq 126 \mathrm{mg} / \mathrm{dL}$, dyslipidaemia equals 1 if total cholesterol is $\geq 200 \mathrm{mg} / \mathrm{dL}$, and the inflammation dummy equals 1 if the high sensitivity C-reactive protein exceeds $2 \mathrm{mg} / \mathrm{dL}$. The results from the probit estimates indicate that long work hours are not associated with prediabetes, dyslipidaemia, or inflammation. However, relative to working $31-40$ 


\section{WH and obesity}

The association between long work hours and general (BMI-based) or central (WCbased) obesity is depicted in Tables 5 and 6, respectively. ${ }^{20}$ In Table 5, which reports ordered probit estimates for BMI-based obesity, although long work hours are significantly and negatively correlated with obesity when no controls are included, significance vanishes once other covariates are introduced (see columns 1 and 2). Likewise, the results for actual weekly work hours (columns 3 and 4) provide no evidence that work hours are associated with obesity. Even when the sample is restricted to individuals working more than 40 hours (column 5), we observe no significant relation.

\section{Table 5}

Ordered probit estimates for long work hours on BMI-based obesity: 1991-2009.

Source: China Health and Nutrition Survey 1991, 1993, 1997, 2000, 2004, 2006, and 2009.

\begin{tabular}{lccccc}
\hline Variables & $(1)$ & $(2)$ & $(3)$ & $(4)$ & $(5)$ \\
\hline $11 \leq \mathrm{WH} \leq 30$ & $-0.0931^{*}$ & 0.0387 & & & \\
& $(0.049)$ & $(0.053)$ & & & \\
$41 \leq \mathrm{WH} \leq 50$ & $-0.2532^{* * *}$ & -0.0166 & & & \\
& $(0.026)$ & $(0.034)$ & & & \\
$\mathrm{WH} \geq 51$ & $-0.1003^{* * *}$ & -0.0126 & & & \\
& $(0.029)$ & $(0.036)$ & & & \\
$\mathrm{WH}$ & & & -0.0015 & -0.0003 & 0.0019 \\
& & & $(0.001)$ & $(0.001)$ & $(0.002)$ \\
\hline$N$ & 11034 & 11034 & 11034 & 11034 & 6844 \\
Pseudo $R^{2}$ & 0.005 & 0.061 & 0.0001 & 0.060 & 0.067 \\
\hline
\end{tabular}

The dependent variable is a BMI-based variable (measured on a 4-point scale ranging from 0 to 3 ); $\mathrm{WH}=$ weekly working hours. Specifications (1) and (2) include dummies for working hours (with $31 \leq \mathrm{WH} \leq 40$ as the reference); (2) also includes individual characteristics, family characteristics, provincial dummies (with Liaoning as the reference), and year dummies (with 1991 as the reference); (3)-(5) include actual weekly working hours, with (5) only including employees who work 41 hours per week or more. Specifications (4) and (5) include the same controls as (2). Robust standard errors are in parentheses; ${ }^{*} \mathrm{p}<0.1,{ }^{* *} \mathrm{p}<0.05, * * * \mathrm{p}<0.01$.

To control for individual time-invariant or omitted factors, we also estimate fixedeffects and fixed-effect ordered logit models. As Table 6 shows, obesity is significantly and negatively affected by working either 41-50 hours per week, according to the fixedeffects estimation (column 1), or over 50 hours per week, according to the fixed-effects

hours per week, working 41-50 hours weekly has a significant negative impact on the probability of diabetes. These results are available from the authors upon request.

20 In most models we note that obesity tends to increase with household income. This is particularly pronounced when using WC. Furthermore, those individuals who have a higher education level are less likely to have a higher BMI level. 
ordered logit estimation (column 2). When we use our continuous variable for actual work hours, however, the coefficients are negative (see columns 4 and 5).

\section{Table 6}

Fixed effects estimates for long work hours on BMI-based obesity: 1991-2009.

Source: China Health and Nutrition Survey 1991, 1993, 1997, 2000, 2004, 2006, and 2009.

\begin{tabular}{|c|c|c|c|c|c|}
\hline \multirow[b]{2}{*}{ Variables } & \multicolumn{2}{|c|}{ WH dummies } & \multicolumn{3}{|c|}{ Actual WH } \\
\hline & $\begin{array}{c}(1) \\
\text { Fixed-effects }\end{array}$ & $\begin{array}{c}(2) \\
\text { Fixed-effects } \\
\text { ordered logit }\end{array}$ & $\begin{array}{c}\text { (3) } \\
\text { Fixed-effects }\end{array}$ & $\begin{array}{c}\text { (4) } \\
\text { Fixed-effects } \\
\text { ordered logit }\end{array}$ & $\begin{array}{c}\text { (5) } \\
\text { Fixed-effects } \\
\text { ordered logit }\end{array}$ \\
\hline $11 \leq \mathrm{WH} \leq 30$ & $\begin{array}{l}-0.011 \\
(0.026)\end{array}$ & $\begin{array}{c}0.002 \\
(0.127)\end{array}$ & & & \\
\hline $41 \leq \mathrm{WH} \leq 50$ & $\begin{array}{c}-0.056^{* * *} \\
(0.018)\end{array}$ & $\begin{array}{l}-0.113 \\
(0.073)\end{array}$ & & & \\
\hline $\mathrm{WH} \geq 51$ & $\begin{array}{l}-0.002 \\
(0.019)\end{array}$ & $\begin{array}{c}-0.303^{* * *} \\
(0.106)\end{array}$ & & & \\
\hline WH & & & $\begin{array}{l}-0.0003 \\
(0.001)\end{array}$ & $\begin{array}{c}-0.008^{* * *} \\
(0.003)\end{array}$ & $\begin{array}{l}-0.008^{*} \\
(0.004)\end{array}$ \\
\hline $\begin{array}{l}\text { Observations } \\
R^{2}\end{array}$ & $\begin{array}{l}7576 \\
0.019\end{array}$ & $\begin{array}{c}19269 \\
-\end{array}$ & $\begin{array}{l}7576 \\
0.015\end{array}$ & $\begin{array}{c}19269 \\
-\end{array}$ & $\begin{array}{c}10757 \\
-\end{array}$ \\
\hline $\begin{array}{l}\text { The dependent } \\
\text { work hours. Sp } \\
\text { include weekly } \\
\text { controls are trar }\end{array}$ & $\begin{array}{l}\text { riable is a BMI-b } \\
\text { ifications (1) and } \\
\text { ork hours, with (5) }\end{array}$ & $\begin{array}{l}\text { d variable (meas } \\
\text { include work } \\
\text { ly including em }\end{array}$ & $\begin{array}{l}\text { d on a 4-point sc } \\
\text { r dummies (wit } \\
\text { ees who work } 4\end{array}$ & $\begin{array}{l}\text { ranging from } 0 \\
1 \leq \mathrm{WH} \leq 40 \text { as th } \\
\text { urs per week or } \\
\text { ze. For (1) and ( }\end{array}$ & $\begin{array}{l}\text { 3); } \mathrm{WH}=\text { weekly } \\
\text { ference); (3)-(5) } \\
\text { re. In (1)-(5), the } \\
\text { community-level }\end{array}$ \\
\hline
\end{tabular}

Table 7 reports the probit estimates for the link between long work hours and obesity as measured by WC. Although the results in columns 1 and 2 are similar to those for the BMI measure (Table 5), there is no association between long work hours and central obesity once other factors are controlled for. With regard to actual work hours, the impacts on central obesity are consistently negative, albeit with different significance levels, and no correlation emerges with working over 40 hours per week (see column 5). These findings are consistent with those of Burkhauser and Cawley (2008), who show that different measures of obesity correlate differently with certain outcomes. However, our results do not support a positive association between work time and obesity. 


\section{Table 7}

Probit estimates for long work hours on WC-based obesity: 1993-2009.

Source: China Health and Nutrition Survey 1993, 1997, 2000, 2004, 2006, and 2009.

\begin{tabular}{lccccc}
\hline Variables & $(1)$ & $(2)$ & $(3)$ & $(4)$ & $(5)$ \\
\hline $11 \leq \mathrm{WH} \leq 30$ & $-0.163^{* * *}$ & 0.016 & & & \\
& $(0.062)$ & $(0.082)$ & & & \\
$41 \leq \mathrm{WH} \leq 50$ & $-0.297^{* * *}$ & -0.014 & & & \\
& $(0.036)$ & $(0.054)$ & & & \\
$\mathrm{WH} \geq 51$ & $-0.148^{* * *}$ & -0.066 & & & \\
& $(0.037)$ & $(0.056)$ & & & \\
$\mathrm{WH}$ & & & $-0.003^{* * *}$ & $-0.003^{*}$ & -0.004 \\
& & & $(0.001)$ & $(0.002)$ & $(0.003)$ \\
\hline$N$ & 8793 & 5201 & 8793 & 5201 & 2842 \\
Pseudo $R^{2}$ & 0.007 & 0.115 & 0.001 & 0.116 & 0.131 \\
\hline
\end{tabular}

The dependent variable is a binary WC-based obesity variable; $\mathrm{WH}=$ weekly working hours. Specifications (1) and (2) include work hour dummies (with $31 \leq \mathrm{WH} \leq 40$ as the reference); (2) also includes individual characteristics, family characteristics, provincial dummies (with Liaoning as the reference), and year dummies (with 1993 as the reference); (3)-(5) include actual weekly work hours, with (5) only including employees who work 41 hours per week or more. Specifications (4) and (5) include the same controls as (2). Robust standard errors are in parentheses; $* \mathrm{p}<0.1, * * \mathrm{p}<0.05, * * * \mathrm{p}<0.01$.

Corresponding results for the fixed effects logit model are presented in Table 8. The odds ratios indicate no significant association between long work hours and central obesity when using dummies for weekly work hours (see column 1 of Table 8). Nevertheless, as for actual work hours, we find that working longer hours per week might decrease the odds of central obesity, although the magnitudes are relatively small (see column 3).

\section{Table 8}

Fixed effects logit estimates of WC-based obesity: 1993-2009.

Source: China Health and Nutrition Survey 1993, 1997, 2000, 2004, 2006, and 2009.

\begin{tabular}{lccc}
\hline Variables & $(1)$ & $(2)$ & $(3)$ \\
& WH dummies & Actual WH & Actual WH $(\geq 41)$ \\
\hline $11 \leq \mathrm{WH} \leq 30$ & 1.187 & & \\
$41 \leq \mathrm{WH} \leq 50$ & $(0.383)$ & & \\
& 0.926 & & \\
$\mathrm{WH} \geq 51$ & $(0.172)$ & & \\
& 0.923 & 0.993 & $0.978^{*}$ \\
$\mathrm{WH}$ & $(0.194)$ & $(0.007)$ & $(0.013)$ \\
& & 1381 & 453 \\
\hline
\end{tabular}

The dependent variable is a binary WC-based obesity dummy; WH = weekly work hours. Specification (1) includes work hour dummies (with $31 \leq \mathrm{WH} \leq 40$ as the reference); (2) and (3) include actual weekly work hours, with (3) only including employees who work 41 hours per week or more. Controls include translog wage, age, translog household income, and household size. Standard errors are in parentheses; ${ }^{*} \mathrm{p}<0.1, * * \mathrm{p}<0.05,{ }^{* * *} \mathrm{p}<0.01$. 
Overall, our results provide no strong evidence that long work hours have a major impact on either subjective or objective measures of health. Even when a significant association exists, the size of the effect is small, and in the case of obesity, long work hours actually have a negative effect.

\section{WH and sleep}

According to van der Hulst (2003), long work hours may decrease sleep time, which could in turn have negative health consequences. In fact, as Table 9 shows, relative to the 31-40 hour work week, working 41-50 and over 50 hours per week is likely to decrease daily sleep time (column 2 ). ${ }^{21}$ This observation is supported by the results for actual weekly work hours, which also indicate a significant negative association between work week length and daily sleep time (columns 3-5). Nonetheless, the magnitudes are small: working over 50 hours reduces sleep time by about 10 more minutes than working 31 to 40 hours per week. These results are in line with those of Park, Kim, Chung, and Hisanaga (2001) for South Korea and Maruyama and Morimoto (1996) for Japan. ${ }^{22}$

\section{WH and diet}

Because long work hours might increase unhealthy dietary patterns, we also examine their possible impact on calorie and fat intake. As Table 10 shows, however, little evidence emerges for any such association: only in our subsample of those working over 40 hours per week is there a small negative correlation between work time and fat intake (see column 6). ${ }^{23}$

\footnotetext{
21 Results also indicate that age is consistently and negatively related to daily sleep time. Furthermore, urban respondents are more likely to sleep less in comparison to rural ones.

22 In order to keep the presentation tractable, we only report results of the pooled cross-sectional regressions when analyzing the lifestyle variables. We however also conducted fixed-effects analyses for all the lifestyle variables and these results are available from the authors upon request. The general conclusions of this paper are not affected by the use of panel techniques, because all the estimated coefficients are either insignificant or correspond to the cross-sectional estimates.

23 Results also show that males tend to exhibit higher levels of calorie and fat intakes. Moreover, those with a higher household income level or living in an urban area are more likely to have a higher level of fat intake. A larger household size is related to a decline in individual calorie and fat intake.
} 


\section{Table 9}

OLS estimates for individual sleep time: 2004-2009.

Source: China Health and Nutrition Survey 2004, 2006, and 2009.

\begin{tabular}{lccccc}
\hline Variables & $(1)$ & $(2)$ & $(3)$ & $(4)$ & $(5)$ \\
\hline $11 \leq \mathrm{WH} \leq 30$ & 0.087 & 0.041 & & & \\
& $(0.068)$ & $(0.070)$ & & & \\
$41 \leq \mathrm{WH} \leq 50$ & -0.049 & $-0.099^{* *}$ & & & \\
& $(0.042)$ & $(0.044)$ & & & \\
$\mathrm{WH} \geq 51$ & $-0.111^{* * *}$ & $-0.209^{* * *}$ & & & \\
& $(0.040)$ & $(0.048)$ & & & \\
$\mathrm{WH}$ & & & $-0.005^{* * *}$ & $-0.007^{* * *}$ & $-0.007^{* * *}$ \\
& & & $(0.001)$ & $(0.001)$ & $(0.002)$ \\
\hline$N$ & 4215 & 4215 & 4215 & 4215 & 2045 \\
Adj. $R^{2}$ & 0.002 & 0.034 & 0.005 & 0.036 & 0.033 \\
\hline
\end{tabular}

The sample is restricted to three waves: 2004, 2006, and 2009. The dependent variable is individual sleep time per day; $\mathrm{WH}=$ weekly work hours. Specifications (1) and (2) include work hour dummies (with $31 \leq \mathrm{WH} \leq 40$ as the reference); (2) also includes individual characteristics, family characteristics, provincial dummies (with Liaoning as the reference), and year dummies (with 2004 as the reference); (3)-(5) include actual weekly work hours, with (5) only including employees who work 41 hours per week or more. Specifications (4) and (5) include the same controls as (2). Robust standard errors are in parentheses; ${ }^{*} \mathrm{p}<0.1,{ }^{*} \mathrm{p}<0.05,{ }^{* * *} \mathrm{p}<0.01$.

\section{Table 10}

OLS estimates for long work hours on calorie/fat intake (log-log model): 1991-2009.

Source: China Health and Nutrition Survey 1991, 1993, 1997, 2000, 2004, 2006, and 2009.

\begin{tabular}{lcccccc}
\hline \multirow{2}{*}{ Variables } & \multicolumn{3}{c}{ Calorie intake } & \multicolumn{3}{c}{ Fat intake } \\
\cline { 2 - 7 } & $(1)$ & $(2)$ & $(3)$ & $(4)$ & $(5)$ & $(6)$ \\
\hline $11 \leq \mathrm{WH} \leq 30$ & $0.031^{* *}$ & & & 0.028 & & \\
& $(0.013)$ & & & $(0.024)$ & & \\
$41 \leq \mathrm{WH} \leq 50$ & -0.003 & & & 0.023 & & \\
& $(0.009)$ & & & $(0.015)$ & & \\
$\mathrm{WH} \geq 51$ & 0.009 & & & 0.012 & & \\
& $(0.009)$ & & & $(0.016)$ & & $-0.093^{* *}$ \\
$\mathrm{WH}$ & & -0.014 & -0.005 & & -0.016 & $(0.043)$ \\
& & $(0.011)$ & $(0.024)$ & & $(0.021)$ & 6780 \\
$N$ & 10933 & 10933 & 6780 & 10933 & 10933 & 0.078 \\
Adj. $R^{2}$ & 0.149 & 0.149 & 0.154 & 0.086 & 0.086 & 0.006
\end{tabular}

The dependent variable is translog individual 3-day averaged calorie intake (in kcal) or fat intake (in grams); $\mathrm{WH}=$ weekly work hours. Specifications (1) and (4) include work hour dummies (with $31 \leq \mathrm{WH} \leq 40$ as the reference), as well as individual characteristics, family characteristics, provincial dummies (with Liaoning as the reference), and year dummies (with 1991 as the reference); (2), (3), (5) and (6) include weekly work hours, with (3) and (6) only including employees who work 41 hours per week or more. Specifications (2), (3), (5) and (6) include the same controls as (1). Robust standard errors are in parentheses; ${ }^{*} \mathrm{p}<0.1,{ }^{* *} \mathrm{p}<0.05, * * \mathrm{p}<0.01$ 
Likewise, once other covariates are controlled for, no significant association emerges between long work hours and time spent on food preparation and cooking (see Table 11). ${ }^{24}$ Moreover, the results for actual work hours (even those restricted to $\geq 41$ hours) are similar to those using dummy variables.

\section{Table 11}

OLS estimates for long work hours on food preparation and cooking time: 1991-2009.

Source: China Health and Nutrition Survey 1991, 1993, 1997, 2000, 2004, 2006, and 2009.

\begin{tabular}{lccccc}
\hline Variables & $(1)$ & $(2)$ & $(3)$ & $(4)$ & $(5)$ \\
\hline $11 \leq \mathrm{WH} \leq 30$ & -0.0028 & 0.0111 & & & \\
& $(0.035)$ & $(0.021)$ & & & \\
$41 \leq \mathrm{WH} \leq 50$ & $-0.1341^{* * *}$ & -0.0001 & & & \\
& $(0.017)$ & $(0.015)$ & & & \\
$\mathrm{WH} \geq 51$ & $0.0694^{* * *}$ & 0.0006 & & & \\
& $(0.026)$ & $(0.019)$ & & & \\
$\mathrm{WH}$ & & & 0.0008 & -0.0005 & -0.0007 \\
& & & $(0.001)$ & $(0.000)$ & $(0.001)$ \\
\hline$N$ & 4082 & 4082 & 4082 & 4082 & 2603 \\
Adj. $R^{2}$ & 0.031 & 0.624 & 0.0001 & 0.624 & 0.640 \\
\hline
\end{tabular}

The dependent variable is time (hours/day) spent on preparing and cooking for the family; $\mathrm{WH}=$ weekly work hours. Specifications (1) and (2) include work hour dummies (with $31 \leq \mathrm{WH} \leq 40$ as the reference); (2) also includes individual characteristics, family characteristics, provincial dummies (with Liaoning as the reference), and year dummies (with 1991 as the reference); (3)-(5) include actual weekly work hours, with (5) only including employees who work 41 hours per week or more. Specifications (4) and (5) include the same controls as (2). Robust standard errors are in parentheses; ${ }^{*} \mathrm{p}<0.1,{ }^{* *} \mathrm{p}<0.05,{ }^{* * *} \mathrm{p}<0.01$.

\section{WH and physical activity}

As emphasized by Berniell (2012), the influence of work hours on the probability of physical activity could affect health, and we do in fact observe a significant negative effect of long work hours on the likelihood of sports participation (see Table 12). ${ }^{25}$ This result echoes Xu's (2013) findings for the U.S.

24 We also show that females spend more time on food preparation and cooking, which is the case in most Chinese families.

25 Males are more likely to perform sports activities than females. In addition, a higher household income level is associated with an increased probability of physical activity. 


\section{Table 12}

Probit estimates for long work hours on leisure time/sports: 1997-2009.

Source: China Health and Nutrition Survey 1997, 2000, 2004, 2006, and 2009.

\begin{tabular}{lccccc}
\hline Variables & $(1)$ & $(2)$ & $(3)$ & $(4)$ & $(5)$ \\
\hline $11 \leq \mathrm{WH} \leq 30$ & $-0.336^{* * *}$ & -0.081 & & & \\
& $(0.077)$ & $(0.083)$ & & & \\
$41 \leq \mathrm{WH} \leq 50$ & $-0.229^{* * *}$ & -0.026 & & & \\
& $(0.047)$ & $(0.053)$ & & & \\
$\mathrm{WH} \geq 51$ & $-0.578^{* * *}$ & $-0.216^{* * *}$ & & & \\
& $(0.048)$ & $(0.059)$ & & & \\
$\mathrm{WH}$ & & & $-0.014^{* * *}$ & $-0.006^{* * *}$ & $-0.008^{* *}$ \\
& & & $(0.002)$ & $(0.002)$ & $(0.003)$ \\
\hline$N$ & 6822 & 6822 & 6822 & 6822 & 3086 \\
Pseudo $R^{2}$ & 0.025 & 0.101 & 0.014 & 0.101 & 0.108 \\
\hline
\end{tabular}

The dependent variable is a dummy for sports participation; WH =weekly work hours. Specifications (1) and (2) include work hour dummies (with $31 \leq \mathrm{WH} \leq 40$ as the reference), but (2) also includes individual characteristics, family characteristics, provincial dummies (with Liaoning as the reference), and year dummies (with 1997 as the reference); (3)-(5) include actual weekly work hours, with (5) only including employees who work 41 hours per week or more. Specifications (4) and (5) include the same controls as (2). Robust standard errors are in parentheses; $* \mathrm{p}<0.1, * * \mathrm{p}<0.05, * * * \mathrm{p}<0.01$.

The results related to sedentary activities (e.g., watching TV, reading, writing, or drawing) show that working longer hours (41-50 and over 50 hours per week) significantly reduces the time spent watching TV (see Table 13). When regressed only on individuals working over 40 hours per week, however, this significance diminishes although it still remains negative (column 3). In contrast, we find no association between long work hours and time spent reading, writing, or drawing (columns 4-6).

In sum, the results for the impact of long work hours on lifestyles suggest that a long work week negatively affects sleep time, fat intake, the probability of sports participation, and watching TV, although the magnitudes are small. We find no evidence that work hours are associated with calorie intake or with time spent preparing food, cooking, reading, writing, or drawing. ${ }^{26}$

26 We conducted a number of robustness tests, including partitioning the sample into different employment sectors (state-owned, collective, and private enterprises), different firm sizes, and rural versus urban individuals. Additionally, as in Frijters, Johnston, and Meng (2009), we looked specifically at extremely long work hours (60 hours and more per week). The results were qualitatively similar although some are worth reporting: (i) employees working longer hours in private (rather than state-owned or collective) enterprises are more likely to report ill health; (ii) long work hours also appear to have a stronger association with SRH in urban than in rural areas; and (iii) we find no significant results for extremely long work hours and health. These results are available from the authors upon request. 


\section{Table 13}

OLS estimates for long work hours on sedentary activities: 2004-2009.

Source: China Health and Nutrition Survey 2004, 2006, and 2009.

\begin{tabular}{|c|c|c|c|c|c|c|}
\hline \multirow{2}{*}{ Variables } & \multicolumn{3}{|c|}{ Watching TV } & \multicolumn{3}{|c|}{ Reading, writing, and drawing } \\
\hline & (1) & (2) & (3) & (4) & (5) & (6) \\
\hline \multirow{2}{*}{$11 \leq \mathrm{WH} \leq 30$} & 0.208 & & & 0.176 & & \\
\hline & $(0.178)$ & & & $(0.139)$ & & \\
\hline \multirow[t]{2}{*}{$41 \leq \mathrm{WH} \leq 50$} & $-0.263^{* *}$ & & & 0.035 & & \\
\hline & $(0.125)$ & & & $(0.106)$ & & \\
\hline \multirow[t]{2}{*}{$\mathrm{WH} \geq 51$} & $-0.474^{* * *}$ & & & -0.083 & & \\
\hline & $(0.122)$ & & & $(0.109)$ & & \\
\hline \multirow[t]{2}{*}{ WH } & & $-0.014^{* * *}$ & -0.007 & & -0.004 & -0.005 \\
\hline & & $(0.004)$ & $(0.006)$ & & $(0.003)$ & $(0.005)$ \\
\hline$N$ & 4055 & 4055 & 1953 & 2096 & 2096 & 839 \\
\hline Adj. $R^{2}$ & 0.062 & 0.061 & 0.042 & 0.050 & 0.051 & 0.066 \\
\hline
\end{tabular}

The dependent variable is time (hours/week) spent watching TV/reading, writing, or drawing; WH =weekly work hours. Specifications (1) and (4) include work hour dummies (with $31 \leq \mathrm{WH} \leq 40$ as the reference), as well as individual characteristics, family characteristics, provincial dummies (with Liaoning as the reference), and year dummies (with 2004 as the reference); (2), (3), (5) and (6) include weekly work hours, with (3) and (6) only including employees who work 41 hours per week or more. Specifications (2), (3), (5) and (6) include the same controls as (1). Robust standard errors are in parentheses; ${ }^{*} \mathrm{p}<0.1,{ }^{* *} \mathrm{p}<0.05,{ }^{* *} \mathrm{p}<0.01$.

\section{Conclusions}

This analysis of data from the China Health and Nutrition Survey (CHNS) assesses whether any association exists between long work hours and health among 18- to 65year-old Chinese working more than 11 hours per week. Our study extends the existing literature by using a rich set of health measures, including objective and subjective measures of health, plus a wealth of multilevel confounding factors. We also overcome the potential biases associated with individual time-invariant unobservables by adopting both fixed-effects and fixed-effects ordered logit approaches. Finally, we identify certain pathways through which long work hours might affect individual lifestyles.

The study yields the following main findings. First, working more than 50 hours per week (as opposed to 31-40 hours per week) increases the probability of high blood pressure, although the effect is not very strong: systolic blood pressure about $1 \mathrm{~mm} \mathrm{Hg}$ higher and diastolic blood pressure around $0.5 \mathrm{~mm} \mathrm{Hg}$ higher. Second, long work hours do not seem to lead to either general or central obesity. Third, self-reported health is 
indeed poorer for individuals working long hours than for those working 31-40 hours per week, although here again, the effect is not strong: an approximately -0.12 effect on a 4-scale measure of self-reported health. Finally, long work hours have diverse impacts on different aspects of individual lifestyles. Specifically, they slightly decrease daily sleep time and the probability of sports participation or watching TV. Nonetheless, they do not seem to be associated with diet - not even calorie intake or time spent on food preparation and cooking - or with the sedentary activities of reading, writing, or drawing.

Our analysis is, of course, subject to certain limitations: first, we are unable to take shift work into consideration, which, as Bannai and Tamakoshi (2014) point out, may eliminate the significant negative effects of long work hours noted in other studies. Second, although we restrict our analysis to those working more than 11 hours per week, we cannot completely rule out the endogeneity of long work hours. Third, the potential impact of consistently working long hours on health is still unclear. Further studies thus are needed to clarify this aspect.

Despite these methodological shortcomings, our results do enable tentative conclusions on how long work hours might influence health by affecting individual lifestyles. For example, our findings indicate that long work weeks, especially those over 50 hours long, may shorten the time available for recovery and reduce daily sleep time, leading to insufficient rest that could increase the odds of high blood pressure (Cappuccio et al., 2007; Gangwisch et al., 2006). Likewise, irregular lifestyles associated with long work hours may reduce the probability of physical activity, which can lead to physiological changes (van der Hulst, 2003) like hypertension (high blood pressure in our analysis). Contrary to findings in other studies, however, we find no positive association between long work hours and obesity. On the one hand, there is a slight indication that long work hours could be associated with a lower fat intake and less time spent on sedentary activity like watching TV. On the other hand, long work hours appear to decrease the probability of sports participation. These effects could thus counterbalance each other, resulting in no pronounced association between long work hours and obesity - or perhaps even a negative impact of the former on the latter.

Overall, however, our results provide limited evidence that long work hours in China are seriously affecting health or lifestyles, at least in terms of the health measures used 
in this study. Three possible explanations for this observation come to mind: First, there is a deeply rooted long work hours culture in China (Sartor, 2011), thereby making Chinese workers perhaps more resilient to the adverse effects of long work hours - at least in comparison to Western workers. Second, and related to this long work hours culture, is the fact that, contrary to Western settings, a Chinese worker's job is not the primary source of stress. As pointed out by Xie (2006), the dramatic and rapid change in the social environment has overshadowed the workplace as a major source of stress. A further source of stress in many Western countries is the difficulty to balance work and family life (Spector et al., 2004). Due to the active involvement of the extended family in caring for children, as well as the small family sizes, balancing work and family may be less of a source of stress in China than in Western countries. Third, there is growing evidence that the detrimental effects of working hours are not primarily associated with the length of the work week per se, but, instead, with the extent to which actual work hours deviate from desired work hours (Bassanini \& Caroli, 2014; Bell, Otterbach, \& Sousa-Poza, 2012). Especially in emerging countries, desired work hours may be substantially longer than in more developed countries, and there is ample empirical evidence that the extent of underemployment is more pronounced in emerging economies despite long actual work hours (e.g. Otterbach, 2010). Although we do not have the data to analyze such hours constraints, desired working time in China may be considerably longer than in other countries, which would dampen the negative effects of long work hours in China. As emphasized by Verité (2004), Chinese workers' desire for overtime is quite pronounced. Moreover, according to recent media reports, Chinese employees have been striking for longer work hours in order to increase their wage earnings (Luk \& Wong, 2014; Slaten, 2014).

However, further research is needed to assess whether the long work weeks in China are influencing other health and lifestyle measures, or whether - as our study appears to indicate - the prominent media attention to "Guolaosi" is unfounded. 


\section{Acknowledgments}

This research uses data from the China Health and Nutrition Survey (CHNS). We thank the National Institute of Nutrition and Food Safety, China Center for Disease Control and Prevention; the Carolina Population Center, University of North Carolina at Chapel Hill; the National Institutes of Health (NIH; R01-HD30880, DK056350, and R01HD38700); and the Fogarty International Center, NIH, for financial support for the CHNS data collection and analysis files since 1989. We thank those parties, as well as the China-Japan Friendship Hospital and the Ministry of Health, for support for the CHNS 2009 survey. This present analysis is an output of a scholarship from the Food Security Center at the University of Hohenheim, which is part of the DAAD (German Academic Exchange Service) program "Exceed" and is supported by DAAD and the German Federal Ministry for Economic Cooperation and Development (BMZ). This paper was presented at the 7th GradAB Ph.D Workshop on 'Perspectives on (Un-)Employment' in Nuremberg. We would like to thank the participants, as well as Wencke Gwozdz and an anonymous referee for valuable comments. The usual disclaimer applies. 


\section{References}

Artazcoz, L., Cortes, I., Escriba-Aguir, V., Cascant, L. \& Villegas, R. (2009). Understanding the relationship of long working hours with health status and healthrelated behaviours. Journal of Epidemiology and Community Health, 63, 521-527.

Baetschmann, G., Staub, K.E. \& Winkelmann, R. (2011). Consistent estimation of the fixed effects ordered logit model. IZA Discussion Paper No. 5443.

Bannai, A. \& Tamakoshi, A. (2014). The association between long working hours and health: A systematic review of epidemiological evidence. Scandinavian Journal of Work, Environment and Health, 40, 5-18.

Bassanini, A. \& Caroli, E. (2014). Is work bad for health? The role of constraint vs Choice. IZA Discussion Paper No.7891.

Batis, C., Sotres-Alvarez, D., Gordon-Larsen, P., Mendez, M.A., Adair, L. \& Popkin, B. (2014). Longitudinal analysis of dietary patterns in Chinese adults from 1991 to 2009. British Journal of Nutrition, 111, 1441-1451.

Bell, D., Otterbach, S. \& Sousa-Poza, A. (2012). Work hours constraints and health. Annals of Economics and Statistics, 105/106, 135-154.

Berniell, M.I. (2012). The effects of working hours on health status and health behaviors. CEMFI-UIMP Discussion Paper.

Burkhauser, R.V. \& Cawley, J. (2008). Beyond BMI: The value of more accurate measures of fatness and obesity in social science research. Journal of Health Economics, 27, 519-529.

Cappuccio, F.P., Stranges, S., Kandala, N.B., Miller, M.A., Taggart, F.M., Kumari, M., Ferrie, J.E., Shipley, M.J., Brunner, E.J. \& Marmot, M.G. (2007). Gender-specific associations of short sleep duration with prevalent and incident hypertension: The Whitehall II Study. Hypertension, 50, 693-700.

Casale, G. \& Zhu, C. (2013). Labour administration reforms in China. Geneva: International Labour Office.

Chamberlain, G. (1980). Analysis of covariance with qualitative data. Review of Economic Studies, 47, 225-238.

Chen, G. \& Hamori, S. (2013). Formal and Informal Employment and Income Differentials in Urban China. Journal of International Development, 25, 987-1004.

Cheng, Y., Du, C.L., Hwang, J.J., Chen, I.S., Chen, M.F. \& Su, T.C. (2014). Working hours, sleep duration and the risk of acute coronary heart disease: A case-control study of middle-aged men in Taiwan. International Journal of Cardiology, 171, 419-422.

Das, M. \& van Soest, A. (1999). A panel data model for subjective information on household income growth. Journal of Economic Behavior \& Organization, 40, 409426.

Ferrer-i-Carbonell, A. \& Frijters, P. (2004). How important is methodology for the estimates of the determinants of life satisfaction? The Economic Journal, 114, 641659.

Frijters, P., Johnston, D.W. \& Meng, X. (2009). The mental health cost of long working hours: The case of rural Chinese migrants. Mimeo.

Gangwisch, J.E., Heymsfield, S.B., Boden-Albala, B., Buijs, R.M., Kreier, F., Pickering, T.G., Rundle, A.G., Zammit, G.K. \& Malaspina, D. (2006). Short sleep duration as a risk factor for hypertension: Analyses of the first National Health and Nutrition Examination Survey. Hypertension, 47, 833-839. 
Hayashi, T., Kobayashi, Y., Yamaoka, K. \& Yano, E. (1996). Effect of overtime work on 24-hour ambulatory blood pressure. Journal of Occupational and Environmental Medicine, 38, 1007-1011.

Houdmont, J., Zhou, J. \& Hassard, J. (2011). Overtime and psychological well-being among Chinese office workers. Occupational Medicine (Oxford, England), 61, 270273.

Iwasaki, K., Sasaki, T., Oka, T. \& Hisanaga, N. (1998). Effect of working hours on biological functions related to cardiovascular system among salesmen in a machinery manufacturing company. Industrial Health, 36, 361-367.

Iwasaki, K., Takahashi, M. \& Nakata, A. (2006). Health problems due to long working hours in Japan: Working hours, workers' compensation (Karoshi), and preventive measures. Industrial Health, 44, 537-540.

Lei, X., Yin, N. \& Zhao, Y. (2012). Socioeconomic status and chronic diseases: The case of hypertension in China. China Economic Review, 23, 105-121.

Liu, Y. \& Tanaka, H. (2002). Overtime work, insufficient sleep, and risk of non-fatal acute myocardial infarction of Japanese men. Occupational and Environmental Medicine, 59, 447-451.

Luk, L. \& Wong, C.H. (2014). Foxconn workers walk off job at Chinese plant. http://www.wsj.com/articles/foxconn-workers-walk-off-job-at-chinese-plant1412854102 (Accessed on 12/10/2014).

Maruyama, S. \& Morimoto, K. (1996). Effects of long workhours on life-style, stress and quality of life among intermediate Japanese managers. Scandinavian Journal of Work, Environment and Health, 22, 353-359.

Ministries of Health and Science and Technology \& the National Bureau of Statistics of the People's Republic of China, (2004). The nutrition and health status of the Chinese people. Beijing: State Information Office.

Mishra, V. \& Smyth, R. (2013). Work hours in Chinese enterprises: Evidence from matched employer-employee data. Industrial Relations Journal, 44, 57-77.

Monet, C. (2014). Working to death in China: A look at the nation with the highest instance of death from overwork in the world. http://thediplomat.com/2014/03/working-to-death-in-china/ (Accessed on 07/09/2014).

Nagashima, S., Suwazono, Y., Okubo, Y., Uetani, M., Kobayashi, E., Kido, T. \& Nogawa, K., (2007). Working hours and mental and physical fatigue in Japanese workers. Occupational Medicine (Oxford, England), 57, 449-452.

Nakanishi, N., Yoshida, H., Nagano, K., Kawashimo, H., Nakamura, K. \& Tatara, K. (2001). Long working hours and risk for hypertension in Japanese male white collar workers. Journal of Epidemiology and Community Health, 55, 316-322.

Ning, G. \& Bloomgarden, Z. (2013). Diabetes in China: Prevalence, diagnosis, and control. Journal of Diabetes, 5, 372.

Nishikitani, M., Nakao, M., Karita, K., Nomura, K. \& Yano, E. (2005). Influence of overtime work, sleep duration, and perceived job characteristics on the physical and mental status of software engineers. Industrial Health, 43, 623-629.

Oster, S. (2014). They're dying at their desks in China as epidemic of stress proves fatal. http://www.bloomberg.com/news/2014-06-29/is-work-killing-you-in-chinaworkers-die-at-their-desks.html (Accessed on 07/09/2014).

Otterbach, S. (2010). Mismatches between actual and preferred work time: Empirical evidence of hours constraints in 21 countries. Journal of Consumer Policy, 33, 143161. 
Park, J., Kim, Y., Cho, Y., Woo, K.-H., Chung, H.K., Iwasaki, K., Oka, T., Sasaki, T. \& Hisanaga, N. (2001). Regular overtime and cardiovascular functions. Industrial Health, 39, 244-249.

Park, J., Kim, Y., Chung, H.K. \& Hisanaga, N. (2001). Long working hours and subjective fatigue symptoms. Industrial Health, 39, 250-254.

Park, J., Yi, Y. \& Kim, Y. (2010). Weekly work hours and stress complaints of workers in Korea. American Journal of Industrial Medicine, 53, 1135-1141.

Sartor, V. (2011). Why all the hard work? http://www.bjreview.com.cn/eye/txt/201112/26/content 416231.htm\# (Accessed on 12/10/2014).

Shields, M. (1999). Long working hours and health. Health Reports, 11, 33-48.

Slaten, K. (2014). Thousands of Foxconn workers strike again in Chongqing for better wages, benefits. http://www.chinalaborwatch.org/newscast/395 (Accessed on 12/10/2014).

Smyth, R., Qian, X., Nielsen, I. \& Kaempfer, I. (2013). Working hours in supply chain Chinese and Thai Factories: Evidence from the Fair Labor Association's 'Soccer Project'. British Journal of Industrial Relations, 51, 382-408.

Sparks, K., Cooper, C., Fried, Y. \& Shirom, A. (1997). The effects of hours of work on health: A meta-analytic review. Journal of Occupational and Organizational Psychology, 70, 391-408.

Spector, P., Cooper, C., Poelmans, S., Allen, T., O'Driscoll, M., Sanchez, I., Siu, O., Dewe, P., Hart, P. \& Lu, L. (2004). A cross-national comparative study of workfamily stressors, working hours and well-being: China and Latin America versus the Anglo world. Personnel Psychology, 57, 119-142.

Tang, D. (2013). Young, middle-aged Chinese worry about health: Survey. http://www.globaltimes.cn/content/772712.shtml (Accessed on 07/09/2014).

Uehata, T. (1978). A study on death from overwork. (I) Considerations about 17 cases. Sangyo Igaku (Japanese Journal of Industrial Health), 20, 479.

Uehata, T. (1991). Long working hours and occupational stress-related cardiovascular attacks among middle-aged workers in Japan. Journal of Human Ergology, 20, 147153.

Van der Hulst, M. (2003). Long workhours and health. Scandinavian Journal of Work, Environment and Health, 29, 171-188.

Verité, (2004). Excessive overtime in Chinese supplier factories: Causes, impacts and recommendations for action. Verité Research Paper, Massachusetts: Amherst.

Wada, K., Katoh, N., Aratake, Y., Furukawa, Y., Hayashi, T., Satoh, E., Tanaka, K., Satoh, T. \& Aizawa, Y. (2006). Effects of overtime work on blood pressure and body mass index in Japanese male workers. Occupational Medicine (Oxford, England), 56, 578-580.

Xie, J.L. (2006). Cross-cultural differences in stress and coping mechanisms - the case of China. Global Workforce Roundtable Member Teleconference. Boston College Center for Work and Family.

Xie, S. \& Mo, T. (2014). The impact of education on health in China. China Economic Review, 29, 1-18.

$\mathrm{Xu}, \mathrm{X}$. (2013). The business cycle and health behaviors. Social Science and Medicine, 77, 126-136.

Xi, B., Liang, Y., He, T., Reilly, K.H., Hu, Y., Wang, Q., Yan, Y. \& Mi, J. (2012). Secular trends in the prevalence of general and abdominal obesity among Chinese adults, 1993-2009. Obesity Reviews, 13, 287-296. 
Yan, S., Li, J., Li, S., Zhang, B., Du, S., Gordon-Larsen, P., Adair, L. \& Popkin, B. (2012). The expanding burden of cardiometabolic risk in China: The China Health and Nutrition Survey. Obesity Reviews, 13, 810-821.

Yang, H., Schnall, P.L., Jauregui, M., Su, T.C. \& Baker, D. (2006). Work hours and self-reported hypertension among working people in California. Hypertension, 48, 744-750.

Zhang, B., Zhai, F.Y., Du, S.F. \& Popkin, B.M. (2014). The China Health and Nutrition Survey, 1989-2011. Obesity Reviews, 15, 2-7.

Zhao, Z. (2008). Health demand and health determinants in China. Journal of Chinese Economic and Business Studies, 6, 77-98.

Zhou, B. \& Cooperative Meta-Analysis Group of the Working Group on Obesity in China, (2002). Predictive values of body mass index and waist circumference for risk factors of certain related diseases in Chinese adults - study on optimal cut-off points of body mass index and waist circumference in Chinese adults. Biomedical and Environmental Sciences, 15, 83-96. 


\section{Appendix:}

\section{Table A1}

Descriptive statistics.

Source: China Health and Nutrition Survey 1991, 1993, 1997, 2000, 2004, 2006, and 2009.

\begin{tabular}{|c|c|c|c|}
\hline Variable & Observation & Mean & Std. Dev. \\
\hline \multicolumn{4}{|l|}{ Dependent variables } \\
\hline High blood pressure $^{\mathrm{a}}$ & 11034 & 0.15 & 0.36 \\
\hline Self-reported health status & 5300 & 2.92 & 0.70 \\
\hline Daily sleep time (hours/day) & 4215 & 7.89 & 1.06 \\
\hline Caloric intake (kcal) & 10933 & 2393.05 & 883.19 \\
\hline Fat intake $(\mathrm{g})$ & 10933 & 81.45 & 70.75 \\
\hline Time spent on food preparation and cooking (hours/day) & 4082 & 0.22 & 0.46 \\
\hline Physical activity a & 6822 & 0.18 & 0.38 \\
\hline Watching TV (hours/week) & 4055 & 4.36 & 2.75 \\
\hline Reading, writing and drawing (hours/week) & 2096 & 1.95 & 1.84 \\
\hline \multicolumn{4}{|l|}{ Individual controls } \\
\hline Weekly work hours (hours/week) & 11034 & 46.79 & 11.74 \\
\hline Age & 11034 & 38.71 & 10.43 \\
\hline Gender $^{\mathrm{a}}$ & 11034 & 0.59 & 0.49 \\
\hline Marital status ${ }^{\text {a }}$ & 11034 & 0.84 & 0.36 \\
\hline \multicolumn{4}{|l|}{ Education categories } \\
\hline Illiterate $^{\mathrm{a}}$ & 11034 & 0.02 & 0.15 \\
\hline Primary school ${ }^{\mathrm{a}}$ & 11034 & 0.15 & 0.36 \\
\hline Middle school $^{\mathrm{a}}$ & 11034 & 0.36 & 0.48 \\
\hline High school $^{\text {a }}$ & 11034 & 0.22 & 0.41 \\
\hline Technical school $^{\mathrm{a}}$ & 11034 & 0.13 & 0.33 \\
\hline University or higher $^{\mathrm{a}}$ & 11034 & 0.12 & 0.32 \\
\hline \multicolumn{4}{|l|}{ Activity levels } \\
\hline Very light ${ }^{\mathrm{a}}$ & 11034 & 0.26 & 0.44 \\
\hline Light $^{\mathrm{a}}$ & 11034 & 0.30 & 0.46 \\
\hline Moderate $^{\text {a }}$ & 11034 & 0.30 & 0.46 \\
\hline Heavy $^{a}$ & 11034 & 0.13 & 0.34 \\
\hline Very heavy $^{\mathrm{a}}$ & 11034 & 0.01 & 0.12 \\
\hline Medical insurance $^{\mathrm{a}}$ & 11034 & 0.66 & 0.47 \\
\hline Urban $^{\mathrm{a}}$ & 11034 & 0.51 & 0.50 \\
\hline \multicolumn{4}{|l|}{ Risk factors } \\
\hline General obesity: BMI & 11034 & 1.34 & 0.68 \\
\hline Central obesity: waist circumference ${ }^{a}$ & 8793 & 0.24 & 0.43 \\
\hline Smoking & 11034 & 0.62 & 0.90 \\
\hline Heavy drinking ${ }^{\text {a }}$ & 11034 & 0.19 & 0.39 \\
\hline \multicolumn{4}{|l|}{ Working conditions } \\
\hline Log (wage) & 11034 & 5.92 & 1.09 \\
\hline Formal employment ${ }^{\mathrm{a}}$ & 11034 & 0.72 & 0.45 \\
\hline \multicolumn{4}{|l|}{ Type of work unit } \\
\hline Three-capital enterprise ${ }^{a}$ & 11034 & 0.01 & 0.10 \\
\hline Government $^{\mathrm{a}}$ & 11034 & 0.35 & 0.48 \\
\hline State service or institute ${ }^{a}$ & 11034 & 0.20 & 0.40 \\
\hline State-owned enterprise ${ }^{\mathrm{a}}$ & 11034 & 0.14 & 0.35 \\
\hline Small collective enterprise ${ }^{a}$ & 11034 & 0.05 & 0.22 \\
\hline
\end{tabular}




\begin{tabular}{lccc} 
Large collective enterprise $^{\mathrm{a}}$ & 11034 & 0.08 & 0.27 \\
Family contract farming $^{\mathrm{a}}$ & 11034 & 0.01 & 0.11 \\
Private/individual enterprise $^{\mathrm{a}}$ & 11034 & 0.15 & 0.36 \\
\hline Family controls & 11034 & 10.07 & 0.75 \\
\hline Log (household income adjusted to 2011) $_{\text {Household size }}$ & 11034 & 3.84 & 1.32 \\
Drinking water $^{\mathrm{a}}$ & 11034 & 0.94 & 0.24 \\
Sanitation $^{\text {a }}$ & 11034 & 0.58 & 0.49 \\
Electricity $^{\text {a }}$ & 11034 & 0.996 & 0.06 \\
\hline Health facilities (community level) $^{\text {Location of health facility }}{ }^{\mathrm{a}}$ & & & \\
\hline Distance to this health facility $(\mathrm{km})$ & 11034 & 0.62 & 0.49 \\
\hline
\end{tabular}

The data for self-reported health status are from 1997 to 2006 and for waist circumference are from 1993 to 2009. The dependent variables are high blood pressure (a binary dummy: 1=yes, $0=$ no), self-reported health status (measured on a 4-point scale: $1=$ poor, $2=$ fair, $3=$ good, $4=$ excellent), daily sleep time, calorie/fat intake, time spent on food preparation and cooking, physical activity, and sedentary activity (watching TV, reading, writing, or drawing). BMI is measured on a 4 -point scale $(0=$ underweight, $1=$ normal weight, $2=$ overweight and $3=$ obese); waist circumference is a dichotomous variable. Smoking behavior is measured on a 4-point scale (based on number of cigarettes smoked, NCS): $0=$ nonsmoker, $1=1 \leq \mathrm{NCS} \leq 10,2=11 \leq \mathrm{NCS} \leq 20$, and $3=\mathrm{NCS}>20$. The location of health facilities in the community is a dummy variable that equals 1 if a health facility is located in the village/neighborhood and 0 if in another village/town/city or in the respondent's city but in a different neighborhood.

a dummy variables.

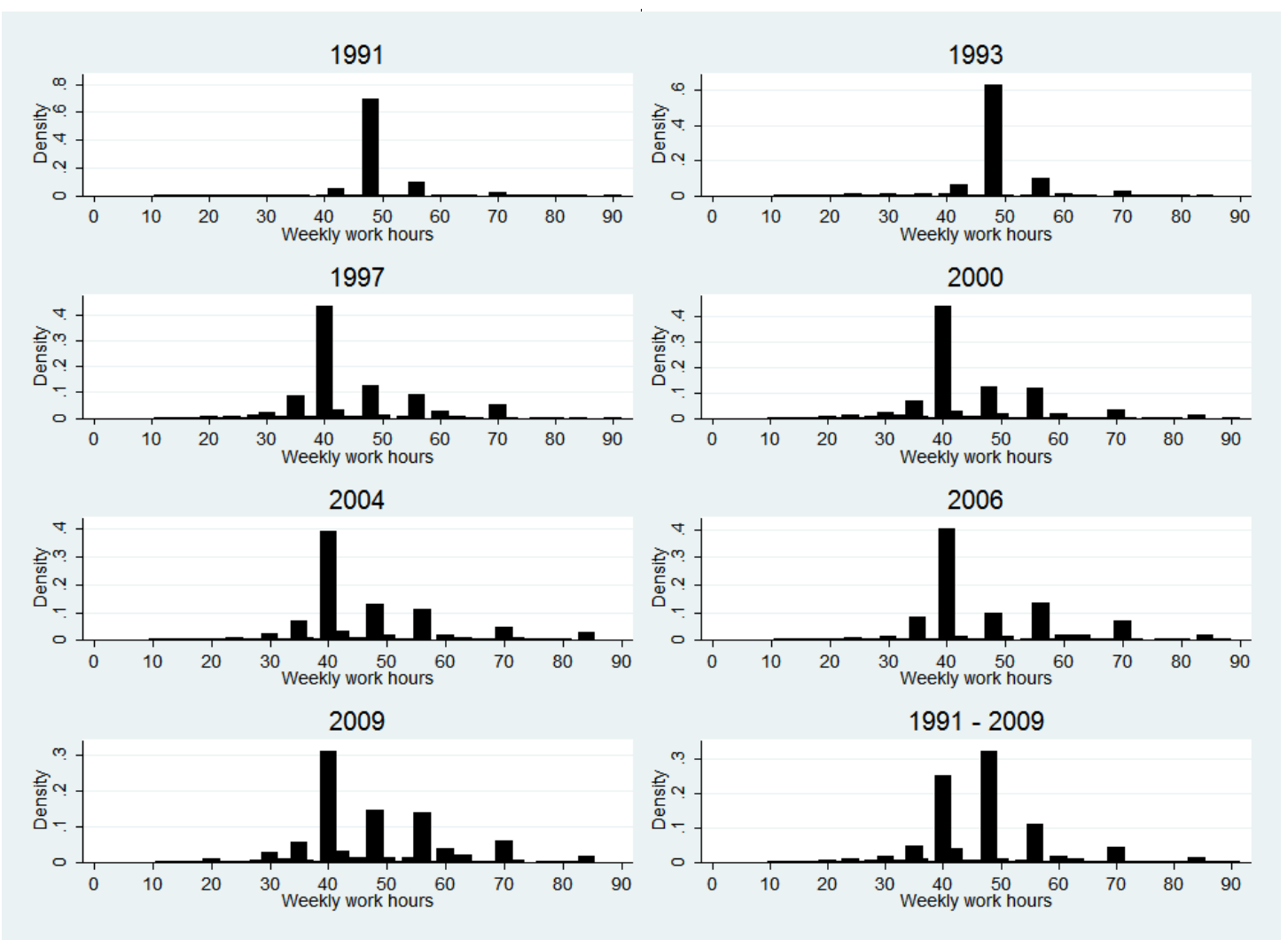

Source: China Health and Nutrition Survey 1991, 1993, 1997, 2000, 2004, 2006, and 2009.

Fig. A1 The distribution of weekly work hours: 1991-2009. 


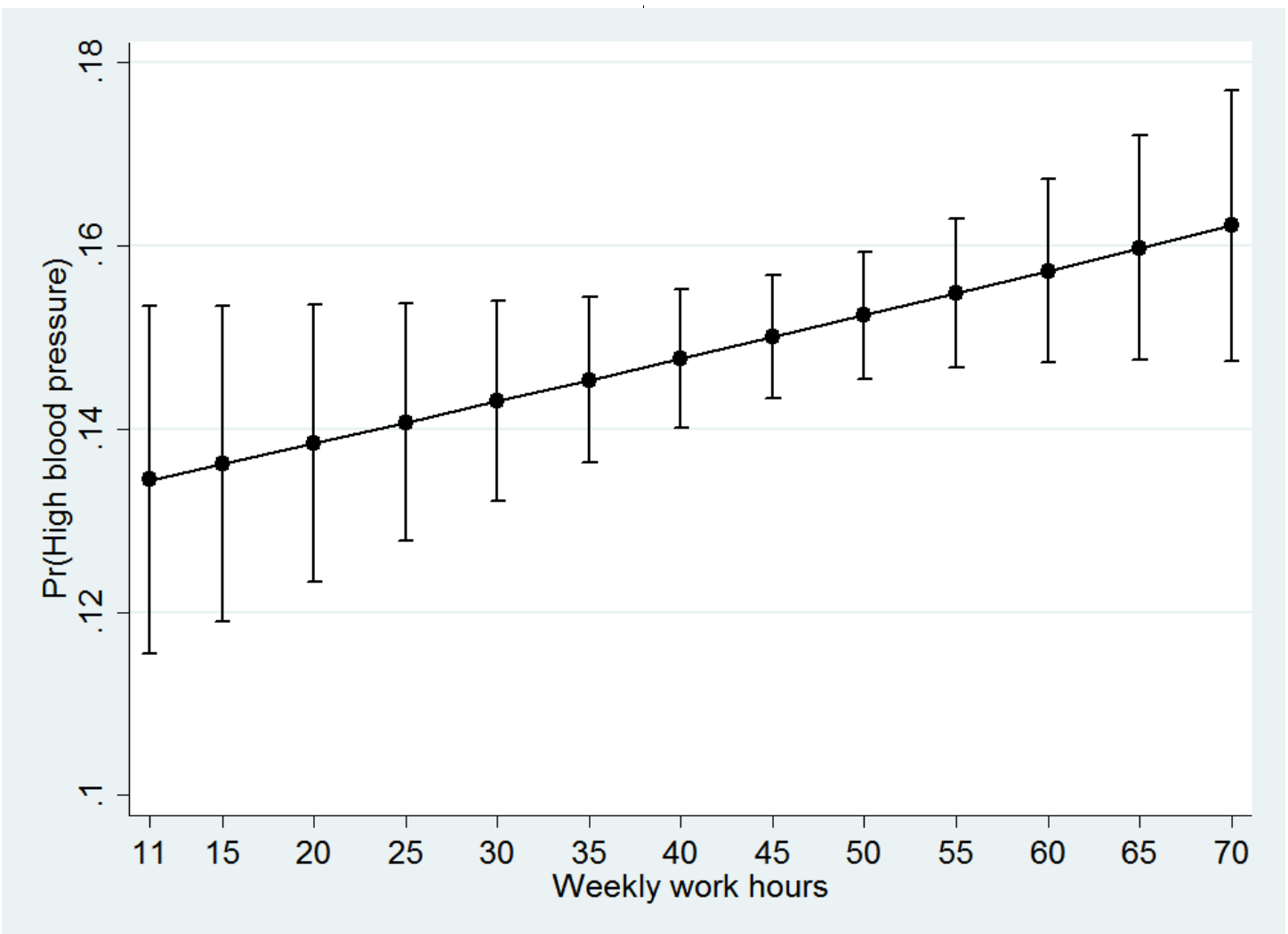

Source: China Health and Nutrition Survey 1991, 1993, 1997, 2000, 2004, 2006, and 2009.

Fig. A2 Marginal effects of weekly work hours on probability of high blood pressure.

\section{Table A2}

Health measures from 1991 to 2009 (in percentage).

Source: China Health and Nutrition Survey 1991, 1993, 1997, 2000, 2004, 2006, and 2009.

\begin{tabular}{lcccccccc}
\hline Health measures & All & 1991 & 1993 & 1997 & 2000 & 2004 & 2006 & 2009 \\
\hline Self-reported health & & & & & & & & \\
\hline 1=Poor & 2.1 & N.A & N.A & 2.0 & 1.8 & 1.9 & 2.5 & N.A \\
2=Fair & 22.7 & N.A & N.A & 17.5 & 23.6 & 25.6 & 24.5 & N.A \\
3=Good & 56.3 & N.A & N.A & 65.1 & 52.6 & 54.1 & 52.2 & N.A \\
4=Excellent & 18.9 & N.A & N.A & 15.4 & 22.0 & 18.4 & 20.8 & N.A \\
\hline High blood pressure & 15.1 & 11.2 & 12.5 & 15.1 & 17.7 & 17.9 & 14.0 & 19.3 \\
\hline Overweight and general obesity & & & & & & & & \\
\hline Overweight & 26.5 & 20.3 & 24.4 & 27.0 & 29.4 & 30.9 & 29.1 & 31.6 \\
General obesity & 6.4 & 3.5 & 3.4 & 5.8 & 7.7 & 8.7 & 8.8 & 9.6 \\
\hline Abdominal obesity & 24.3 & N.A & 12.9 & 19.8 & 24.8 & 29.5 & 29.5 & 31.7 \\
\hline
\end{tabular}

Self-reported health (1997-2006) is measured on a 4-point scale (1=poor, 2=fair, 3=good and 4=excellent). High blood pressure (1991-2009) is a binary variable $(1=$ yes, $0=$ no). Based on the criteria of Working Group on Obesity in China (WGOC), overweight and general obesity (1991-2009) based on body mass index (BMI) are defined as 24 $\leq \mathrm{BMI}<28$ and $\mathrm{BMI} \geq 28 \mathrm{~kg} / \mathrm{m}^{2}$, respectively. Abdominal obesity (1993-2009) is defined as a waist circumference $\geq$ $85 \mathrm{~cm}$ for men and $\geq 80 \mathrm{~cm}$ for women. N.A denotes not available. 


\section{Table A3}

OLS estimates of blood pressure: 1991-2009.

Source: China Health and Nutrition Survey 1991, 1993, 1997, 2000, 2004, 2006, and 2009.

\begin{tabular}{|c|c|c|c|c|c|c|}
\hline \multirow{2}{*}{ Variables } & \multicolumn{3}{|c|}{ Systolic blood pressure } & \multicolumn{3}{|c|}{ Diastolic blood pressure } \\
\hline & (1) & (2) & (3) & (4) & $(5)$ & (6) \\
\hline $11 \leq \mathrm{WH} \leq 30$ & $\begin{array}{l}-0.413 \\
(0.582)\end{array}$ & & & $\begin{array}{l}-0.282 \\
(0.426)\end{array}$ & & \\
\hline $41 \leq \mathrm{WH} \leq 50$ & $\begin{array}{c}0.305 \\
(0.368)\end{array}$ & & & $\begin{array}{c}0.129 \\
(0.263)\end{array}$ & & \\
\hline $\mathrm{WH} \geq 51$ & $\begin{array}{l}0.972^{* *} \\
(0.405)\end{array}$ & & & $\begin{array}{l}0.594^{* *} \\
(0.293)\end{array}$ & & \\
\hline WH & & $\begin{array}{c}0.032^{* * *} \\
(0.012)\end{array}$ & $\begin{array}{c}0.013 \\
(0.020)\end{array}$ & & $\begin{array}{c}0.017^{*} \\
(0.009)\end{array}$ & $\begin{array}{c}0.004 \\
(0.014)\end{array}$ \\
\hline$N$ & 11034 & 11034 & 6844 & 11034 & 11034 & 6844 \\
\hline Adj. $R^{2}$ & 0.268 & 0.268 & 0.271 & 0.238 & 0.238 & 0.242 \\
\hline
\end{tabular}

The dependent variable is continuous blood pressure (systolic blood pressure/diastolic blood pressure); $\mathrm{WH}=$ weekly work hours. Specifications (1) and (4) include work hour dummies (with $31 \leq \mathrm{WH} \leq 40$ as the reference); (2), (3), (5), and (6) include actual weekly work hours, with (3) and (6) only including employees who work 41 hours per week or more. All six specifications also include individual characteristics, risk behaviors (BMI, smoking, and heavy drinking), family characteristics, provincial dummies (with Liaoning as the reference), year dummies (with 1991 as the reference), and the characteristics of health facilities in the community. Robust standard errors are in parentheses; ${ }^{*} \mathrm{p}<0.1,{ }^{* *} \mathrm{p}<0.05, * * * \mathrm{p}<0.01$. 